\title{
NASA Environmentally Responsible Aviation Project's Propulsion Technology Phase I Overview and Highlights of Accomplishments
}

\author{
Kenneth L Suder, John Delaat, Chis Hughes, Dave Arend, and Mark Celestina, ${ }^{1}$ \\ NASA Glenn Research Center, Cleveland, $\mathrm{OH}, 44135$
}

\begin{abstract}
The NASA Environmentally Responsible Aviation (ERA) Project is focused on developing and demonstrating integrated systems technologies to TRL 4-6 by 2020 that enable reduced fuel burn, emissions, and noise for futuristic air vehicles. The specific goals aim to simultaneously reduce fuel burn by $50 \%$, reduce Landing and Take-off Oxides of Nitrogen emissions by $75 \%$ relative to the CAEP 6 guidelines, and reduce cumulative noise by 42 Decibels relative to the Stage 4 guidelines. These goals apply to the integrated vehicle and propulsion system and are based on a reference mission of $3000 \mathrm{~nm}$ flight of a Boeing 777-200 with GE90 engines. This paper will focus primarily on the ERA propulsion technology portfolio, which consists of advanced combustion, propulsor, and core technologies to enable these integrated air vehicle systems goals. An overview of the ERA propulsion technologies will be described and highlights of the results obtained during the first phase of ERA will be presented.
\end{abstract}

\section{Nomenclature}

$\begin{array}{ll}\text { ASCR } & \text { Advanced Subsonic Combustor Rig } \\ \text { BPR } & \text { Bypass Ratio } \\ \text { CAEP } & \text { Committee on Aviation Environmental Protection } \\ \text { CFD } & \text { Computational Fluid Dynamics } \\ \text { CMC } & \text { Ceramic Matrix Composite } \\ \text { CRESS } & \text { Counter Rotating Externally Staged Swirler } \\ \text { EBC } & \text { Environmental Barrier Coating } \\ \text { ERA } & \text { Environmentally Responsible Aviation } \\ \text { FPR } & \text { Fan Pressure Ratio } \\ \text { GE } & \text { General Electric } \\ \text { GRC } & \text { Glenn Research Center } \\ \text { GTF } & \text { Geared TurboFan } \\ \text { ICAO } & \text { International Civil Aviation Organization } \\ \text { LTO } & \text { Landing and Take-Off }\end{array}$

\footnotetext{
${ }^{1}$ Aerospace Engineer, Aeronautics Office, 21000 Brookpark Road MS 5-10, AIAA Member. 


$\begin{array}{ll}\text { NOx } & \text { Oxides of Nitrogen } \\ \text { OPR } & \text { Overall Pressure Ratio } \\ \text { OTR } & \text { Over-The-Rotor } \\ \text { P\&W } & \text { Pratt \& Whitney } \\ \text { RQL } & \text { Rich Quench Lean } \\ \text { SFC } & \text { Specific Fuel Consumption } \\ \text { SV } & \text { Soft Vane } \\ \text { TAPS } & \text { Twin Annular Premixing Swirler } \\ \text { TRL } & \text { Technology Readiness Level } \\ \text { UEET } & \text { Ultra Efficient Engine Technology } \\ \text { UHB } & \text { Ultra High Bypass }\end{array}$

\section{Introduction}

The goal of the NASA Environmentally Responsible Aviation (ERA) project is to explore and document the feasibility, benefits, and technical risks of vehicle concepts and enabling technologies identified to have the potential to mitigate the impact of aviation on the environment. Through system-level analysis, promising vehicle and propulsion concepts and technologies will be down-selected based on their potential benefit towards simultaneously achieving fuel burn, noise and emissions metrics consistent with the NASA subsonic transport goals as shown in Table 1 below. ERA is focused on developing and demonstrating technologies to Technology Readiness Level (TRL) 4- 6 by the 2020 time frame as defined by the goals defined in the column identified as $\mathrm{N}+2$ goals of Table 1 (Ref. 1).

These concepts and technologies will then be matured and their performance will be evaluated at the system and sub-system level in relevant environments and across the vehicle fleet (Ref 2). Among the concepts and technologies to be explored are the following:

- Advanced aircraft system architectures that enable simultaneous achievement of noise, Landing Take Off

(LTO) $\mathrm{NO}_{\mathrm{x}}$ and fuel burn goals in the $\mathrm{N}+2$ timeframe (see Table 1 below)

- Drag reduction through laminar flow

- Advanced composite structural concepts for weight reduction

- Low NOx, fuel-flexible combustors

- Integration of advanced UHB engines for noise reduction and fuel burn improvements

In Table 1, the Subsonic Transport System Level Metrics are shown, outlining the environmental fuel burn, noise and emissions reduction goals, the time frame for achieving them, and the baseline defined for comparing with new technologies. Though these goals are aggressive they are based on integrating advanced propulsion and airframe technologies and flying the vehicle through a reference mission and comparing the results to a 1998 baseline mission. To this end, the ERA project is sub-divided into three major subprojects consisting of airframe technology, propulsion technology, and vehicle systems integration. It is evident to achieve the goals defined in the N+2 column of Table 1 significant advancements and technology developments are required. First, to achieve the 50\% fuel burn reduction goal the following technologies are being developed and/or demonstrated: 1) drag reduction by extending the laminar flow regions on the aircraft surfaces using natural and hybrid laminar flow technologies. 2) weight reduction by developing and demonstrating advanced composite structures, and 3) reduction of engine specific fuel consumption by improving both propulsive and thermal efficiency of the gas turbine engines. Similarly, the noise goals are being addressed by the following technologies: 1) reduction of airframe noise by reducing the noise attributed to high lift systems and landing gear, 2) reduction of propulsion noise by addressing fan, core and jet noise, and 3) optimizing propulsion air frame integration to minimize the propulsion airframe aero acoustics. To reduce oxides of nitrogen emissions, ERA is developing advanced concepts to enable a low NOx fuel flexible combustor inclusive of lean direct injection concepts, advanced Ceramic Matrix Composite (CMC) liners with advanced environmental coatings, and combustion control strategies to enable stable lean burn combustion. 


\begin{tabular}{|c|c|c|c|}
\hline & \multicolumn{3}{|c|}{$\begin{array}{c}\text { TECHNOLOGY GENERATIONS } \\
\text { (Technology Readiness Level = 4-6) }\end{array}$} \\
\hline $\begin{array}{c}\text { TECHNOLOGY } \\
\text { BENEFITS* }\end{array}$ & $\mathrm{N}+1(2015)$ & $\mathrm{N}+2\left(2020^{\star *}\right)$ & $\mathrm{N}+3$ (2025) \\
\hline $\begin{array}{c}\text { Noise } \\
\text { (cum below Stage 4) }\end{array}$ & $-32 \mathrm{~dB}$ & $-42 \mathrm{~dB}$ & $-71 \mathrm{~dB}$ \\
\hline $\begin{array}{c}\text { LTO NOx Emissions } \\
\text { (below CAEP 6) }\end{array}$ & $-60 \%$ & $-75 \%$ & $-80 \%$ \\
\hline $\begin{array}{c}\text { Cruise NOx Emissions } \\
\text { (rel. to 2005 best in class) }\end{array}$ & $-55 \%$ & $-70 \%$ & $-80 \%$ \\
\hline $\begin{array}{c}\text { Aircraft Fuel/Energy Consumption } \\
\text { (rel. to 2005 best in class) }\end{array}$ & $-33 \%$ & $-50 \%$ & $-60 \%$ \\
\hline
\end{tabular}

* Projected benefits once technologies are matured and implemented by industry. Benefits vary by vehicle size and mission; $\mathrm{N}+1$ and $\mathrm{N}+3$ values are referenced to a 737-800 with CFM56-7B engines, $N+2$ values are referenced to a 777-200 with GE90 engines

** ERA's time phased approach includes advancing "long-pole" technologies to TRL 6 by 2015

$\ddagger \mathrm{CO}_{2}$ emission benefits dependent on life-cycle $\mathrm{CO}_{2 \mathrm{e}}$ per $\mathrm{MJ}$ for fuel and/or energy source used

Table 1: NASA Subsonic Transport System Level Metrics.

ERA's approach is to work in collaboration with industry and other government agencies using a cost-share approach to develop and demonstrate integrated system technologies. For example, with regard to the combustor development the approach is to utilize experiments and analysis in conjunction with flame tube, sector-rig, and fullscale combustor testing culminating in a full annular combustor test by 2015 to validate the new combustor concept that will meet the emissions goals.

In Figure 1, the fuel burn savings potential from using advanced aircraft technologies available in $2020(\mathrm{~N}+2)$ is shown for both a conventional large twin aisle vehicle with a circular fuselage and an advanced hybrid wing body advanced vehicle configuration (Refs. 3-5). It is predicted that advanced engine technology will contribute between about $15.3 \%$ and $18.5 \%$ of the total savings, depending on airframe type, compared with a large twin aisle aircraft. Similar system studies to predict the contribution of advanced technologies to the ERA noise reduction goals have shown that about $50 \%$ of the noise reduction will be achieved from the advanced propulsion systems incorporating high bypass ratio engines and reduced fan speeds. It is clear that the developments of the advanced propulsion technologies are critical to achieving the ERA goals. In the following sections, the ERA propulsion technology portfolio that consists of advanced combustion, propulsor, and core technologies will be described and the status and highlights of the results obtained during the first phase of ERA will be presented.

\section{Combustion Technologies}

A series of increasingly stringent NOx emission standards by the International Civil Aviation Organization's (ICAO) Committee on Aviation Environmental Protection (CAEP) over the years have limited aviation emissions below 3,000-foot altitude (Ref. 6). These standards cover the landing, takeoff, descent, and taxiing phases of the engine operation (LTO) in a prorated fashion. ERA's goal is to develop and demonstrate a low NOx Fuel flexible combustor that provides a 75\% reduction in oxides of nitrogen below the current standard that was defined at the $6^{\text {th }}$ CAEP meeting, with no increase in particulate matter, while achieving a 50 percent reduction in fuel burned. System studies (Refs. 4-5) indicate that to meet the fuel burn reductions goals, advanced engines will be operating at higher pressures and temperatures that encourage NOx production (see Figure 2). In order to improve specific fuel consumption and simultaneously reduce NOx requires an advanced combustor technology. Therefore, new injector designs and air/fuel mixing concepts, such as lean direct injection, will be required to meet the emissions goals and provide fuel flexibility. Leaner-burn concepts tend to have less stability margin and require fuel staging and combustion control. 


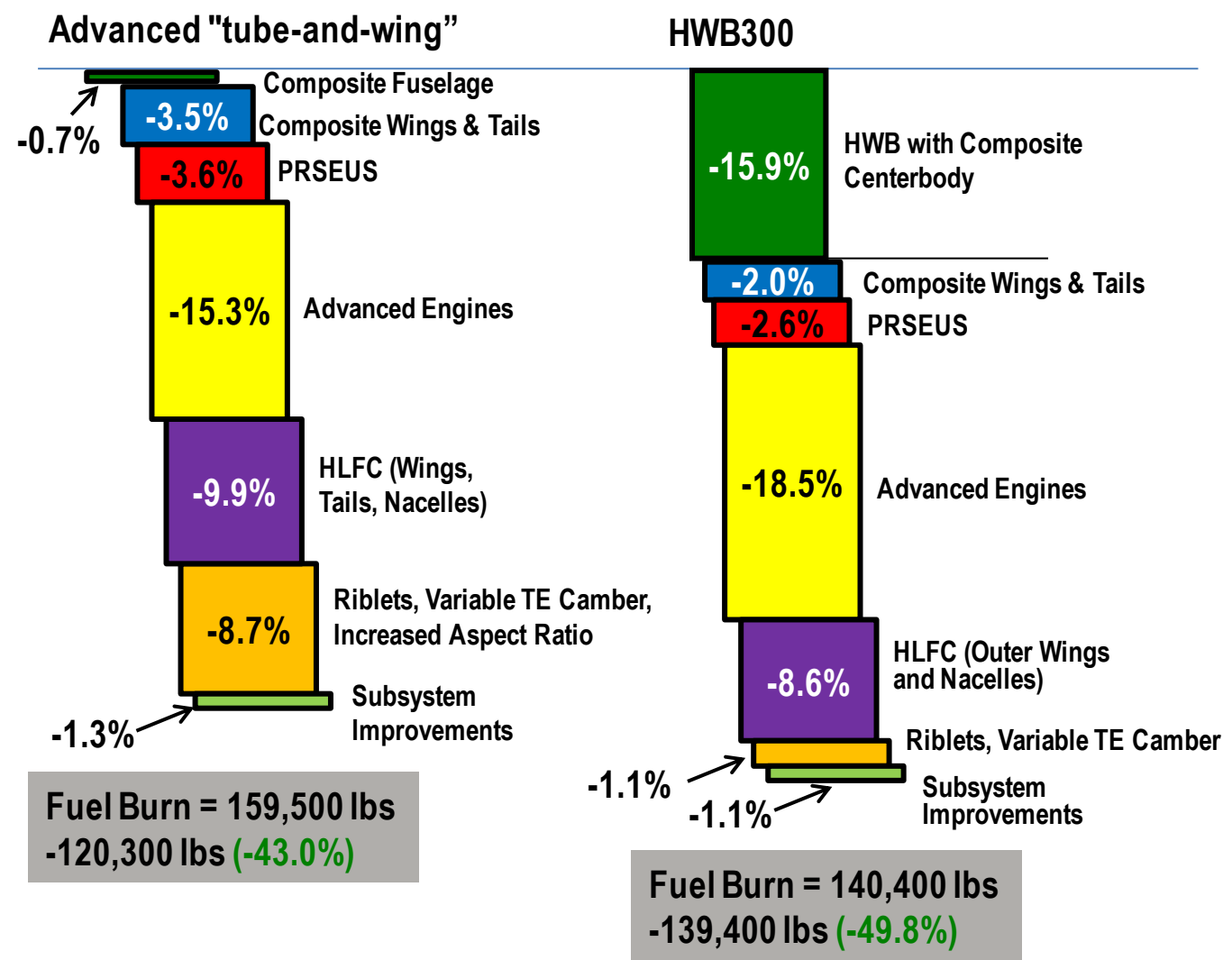

Figure 1: Technology benefits relative to a 1998 Large Twin Aisle (i.e. Boeing 777-200LR) with GE90 engines for both an advanced tube and wing and advanced vehicle configuration.

Therefore, the Technical Challenge for the Low NOx, Fuel Flexible Combustion System is: Demonstrate reductions of LTO NOx by 75\% from CAEP 6 and cruise NOx by 70\% while minimizing the impact on fuel burn at the aircraft system level, without penalties in stability and durability of the engine system. To accomplish this the ERA project approach is to 1) pursue multiple concepts including Lean Partial-Mixed Combustor and Lean Direct Multi-Injection, 2) screen these concepts in flame tube tests and down select the most promising candidates for sector rig and annular combustor development and testing, 3) develop an integrated Ceramic Matrix Composite (CMC) and Environmental Barrier Coating (EBC) liner system to provide more air for fuel/air mixing resulting from the reduction in cooling air required for a metallic liner, and 4) develop/demonstrate combustion control capabilities to provide stability for lean burn systems. The combustor liner development status ard results will be presented with the other materials activities in the core technology section of this paper. In the following section on Results we will discuss a) the results of the combustor concept development and b) the combustion control development activities.

\section{A. Combustor Concept Development: Results and Discussion}

NASA ERA is contracted with General Electric (GE) Aviation and Pratt \& Whitney (P\&W) in a 50/50 cost share to develop the new lean burn concepts (see Figure 3) and demonstrate these in a sector rig test which simulates the pressures and temperatures of a relevant engine environment (Ref. 7). The NASA Glenn Research Center (GRC) Advanced Subsonic Combustor Rig (ASCR) facility has been upgraded to provide combustor entrance conditions up to a pressure of 900 psia and temperature up to $1300 \mathrm{~F}$ and will be used for the sector rig testing. 


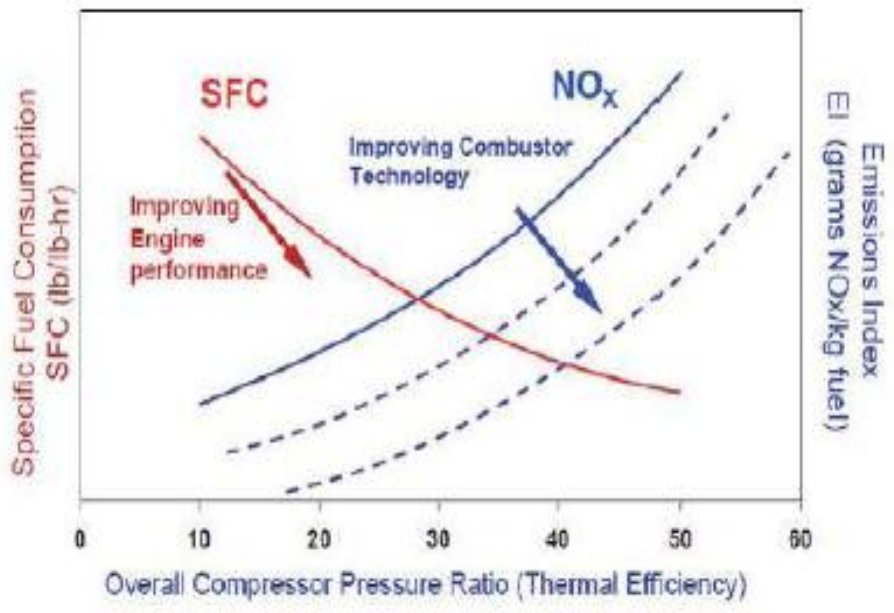

Figure 2: Impact of overall pressure ratio on NOx formation.

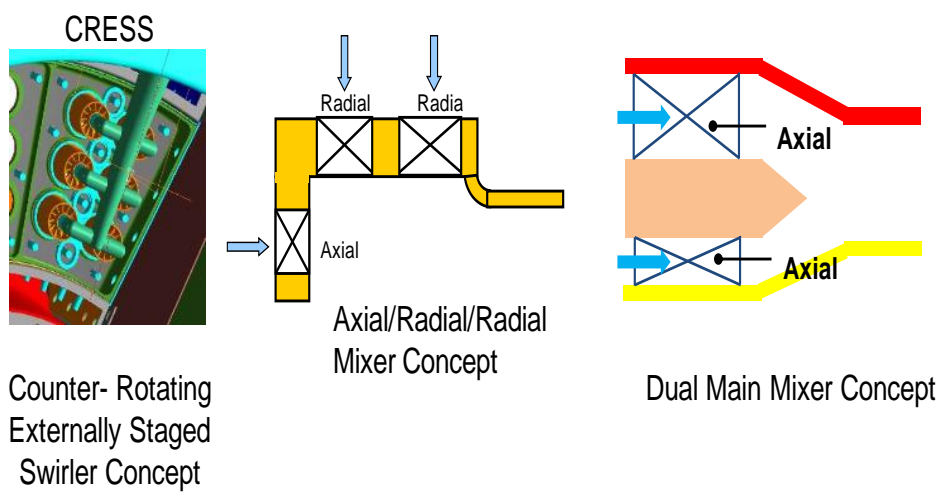

Figure 3: Candidate lean burn injector /mixer concepts.

GE Aviation has designed and tested advanced lean burn combustor concepts extended from the Twin Annular Premixing Swirler (TAPS), which was developed under GE and NASA sponsored AST and UEET programs. Most recently, the TAPS combustor was developed for application in the new GEnx-1B and GEnx-2B engines that power the new Boeing 787 and 747-8 wide-body aircraft, respectively. The TAPS design consisted of independently controlled, swirl stabilized, annular flames for low power (pilot) and high power (main) operation. The central pilot flame provided good low power operability and low $\mathrm{CO}$ and $\mathrm{HC}$ emissions. The main flame is concentric with the pilot flame and was designed to produce low NOx emissions during high power operation. Under the ERA program, combustor concepts were designed for a High OPR engine cycle that meets the noise, fuel burn, and emissions NASA N+2 goals as part of an overall aircraft system. The combustion system incorporated advanced liner materials benefitting both durability and emissions by decreasing cooling air requirements and enabling a higher fraction of combustion air in the main mixer for lower NOx emissions.

Several advanced TAPS injector concepts were designed and tested in a flame tube configuration to evaluate emissions, combustion dynamics, and auto ignition margin up to full operating conditions. A sampling of the results for 13 of these injector concepts is shown below in Figure 4. The measured NOx emissions index at a low power setting is plotted as a vertical blue bar. The horizontal blue bars indicates GE's estimate of the integrated LTO NOx 
value and should be compared to the black horizontal bar representing the ERA goal of a 75\% reduction in LTO NOX reduction for these power settings. Also, the red and green vertical bars represent the CFD predicted NOx emissions index for the $100 \%$ power settings, so that one can see the range of NOx emissions with power setting for a selected injector design types. Several designs demonstrated acceptable operability margin at takeoff conditions and the LTO emissions predictions based on flame tube data exceeded the ERA target of 75\% below CAEP/6.

Based on testing and analysis results an injector design was selected and was incorporated into an advanced 5-cup sector rig at NASA's ASCR facility. The ASCR facility provides the capability to obtain data over the entire flight envelop including high power operation for inlet conditions up to $1300 \mathrm{~F}$ and $900 \mathrm{psia}$, which correspond to test the conditions required to calculate the ICAO LTO NOx emissions level for engines with an overall pressure ratio of 50:1. These sector rig tests were performed at the NASA Glenn Research Center (GRC) Advanced Subsonic Combustor Rig (ASCR) during the last 6 months of 2012. The GE sector test results are still being analyzed and will not be in included in this report. However, preliminary results indicate the GE combustor concept has the potential to meet the ERA goals.

Pratt \& Whitney $(\mathrm{P} \& \mathrm{~W})$ concepts have included lean-staged multi-point designs, radially staged swirlers, richquench-lean (RQL) combustors, and axially staged combustors. The simplicity, operability, durability, and excellent emissions of the RQL family of combustors have led to the continued use of the concept in P\&W engines. The most recent $\mathrm{P} \& \mathrm{~W}$ combustor TALON X, was developed with support from NASA under the UEET program, and has been selected for the P\&W Geared TurboFan engine on upcoming Airbus, Bombardier and Mitsubishi aircraft. In this effort, $P \& W$ and UTRC are investigating multiple injection points and have used modern tools to improve the mixing of the individual injection points in order to reduce the number of injection points by a factor of 2 compared to previous designs. In a similar fashion, $\mathrm{P} \& \mathrm{~W}$ has revisited the radially staged swirler concepts as well as versions of axially staged combustors.

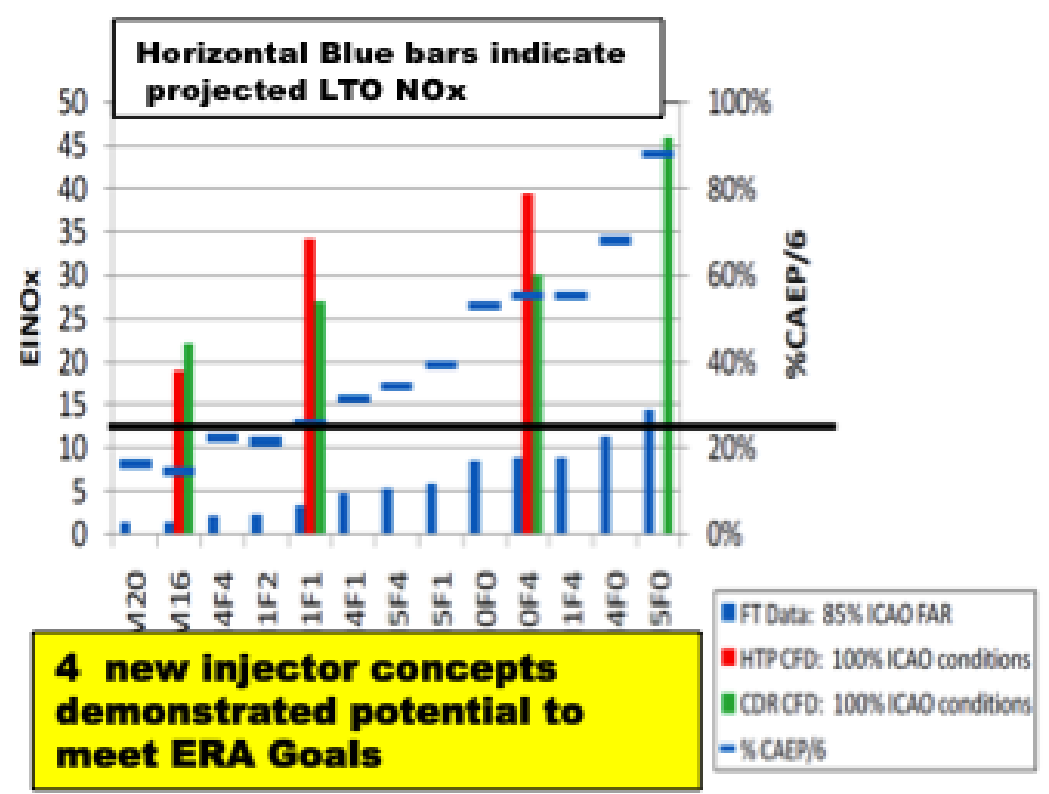

Figure 4: GE flame tube data: NOx emissions index for 13 advanced injector concepts. 


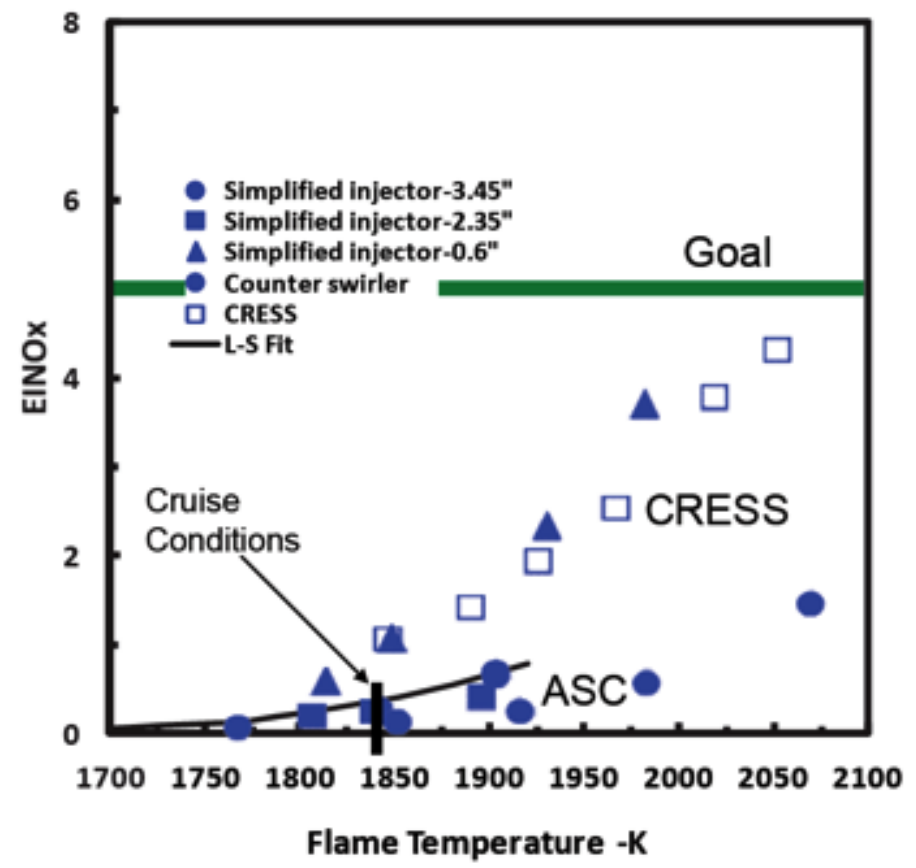

Figure 5: P\&W Flame tube test results at $7 \%$ and $30 \%$ power settings.

Initial testing of the concepts was conducted at UTRC in an idealized Single Nozzle Rig. Results at 7\% and 30\% power settings for various injector configurations and fuel air ratios are shown in Figure 5 and are very encouraging, demonstrating that all the concepts could have emissions results below the goals set by NASA. A few of the concepts performed very well with NOx emissions levels substantially lower than the NASA goals as well as excellent levels of efficiency. Based on additional testing and analysis an injector concept design was selected and has been developed into an advanced 3-cup sector rig. The sector rig was tested at NASA's ASCR facility to measure performance, operability and emissions at test conditions required to calculate the ICAO LTO NOx emissions level. These sector rig tests were completed during the last 6 months of 2012. The P\&W sector test results are still being analyzed and will not be in included in this report. However, preliminary results indicate the P\&W combustor concept has the potential to meet the ERA goals.

ERA also is collaborating with Goodrich, Woodward FST, and Parker Hannifin to design and develop next generation fuel injector concepts. These are more aggressive ideas, but more limited in scope to the injector and its dynamic behavior. These concepts have to demonstrate burning blends of up to $80 \%$ alternative fuel to $20 \%$ of jet fuel. All of these designs are in some form multi-point Lean Direct Injection (LDI) concepts that NASA has been working on during the last two decades for ultra-high pressure operation in which the flame front moves closer to the injectors. (See Figure 6.) Some of these concepts will incorporate fuel-flow control features to prevent instability. While these industry partners will be able to verify their performances at low power combustor settings, they also will verify their performance at higher power settings by using a NASA facility.

A summary of advanced Fuel Injector development follows:

- Goodrich has downselected their concept and completed their Lean-Blow-Off testing. The concept was tested in the high pressure flametube facility at NASA GRC. Testing was not completed due to a fuel leak. The hardware is under repair and will resume testing as soon as possible.

- Woodward has completed the light-Off and Lean-Blow-Off testing of their injector concept. Additional testing is ongoing at their facilty and the injector will be deliverd to NASA for testing in early February of 2013.

- Parker Hannifin has completed the Spray and Lean-Blowoff tests. Parker has developed a new fuel valve actuator which has been miniaturized and has fast response time for combustion control. 

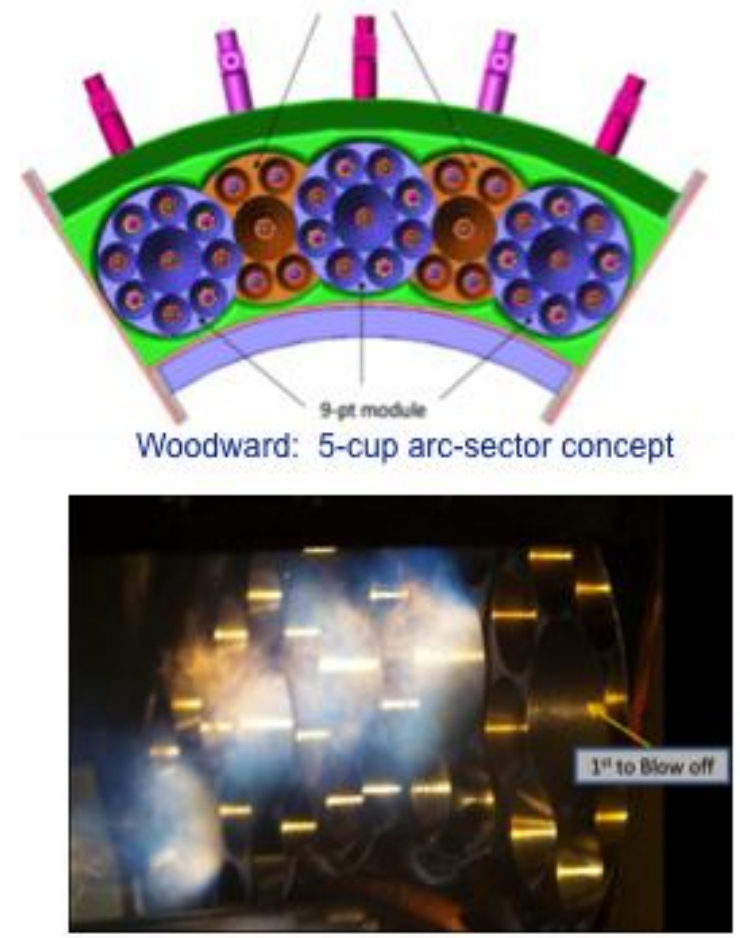

Woodward : Lean-blowout testing (from Woodward contract interim report to NASA dated 06-29-2012)

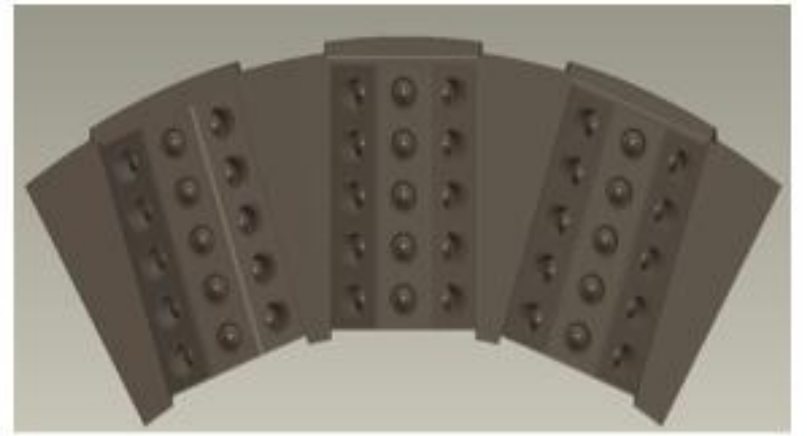

Parker Hanifin: 3-cup arc installation concept

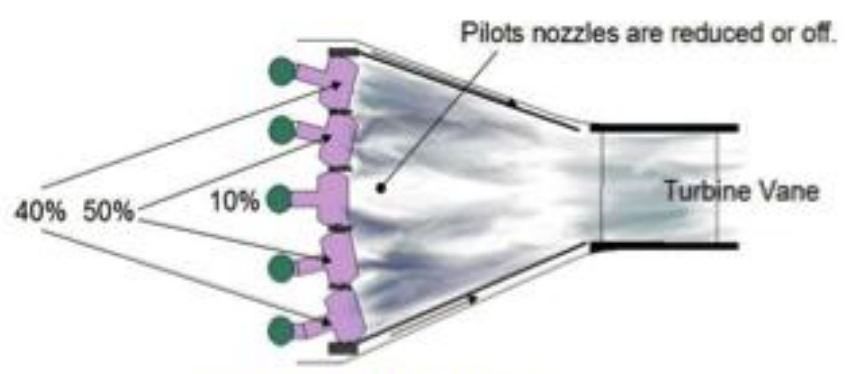

GOODRICH LDI concept At high power, adjacent nozzles become dominant. Combustor runs lean. Core effects are diminished

From ASME Turbo Expo Paper: GT2012-68426

Figure 6: Multi-point lean direct injector (LDI) concepts from Woodward, Parker Hannifin, and Goodrich which are to be tested in the NASA high pressure facility in the January to April, 2013 timeframe.

\section{B. Combustor Control Development: Status and Results}

Future aircraft engines must provide ultra-low emissions and high efficiency at low cost while maintaining the reliability and operability of present day engines. The demands for increased performance and decreased emissions have resulted in advanced combustor designs that are critically dependent on efficient fuel/air mixing and lean operation. However, all combustors, but most notably lean-burning low-emissions combustors, are susceptible to combustion instabilities. These instabilities are typically caused by the interaction of the fluctuating heat release of the combustion process with naturally occurring acoustic resonances. These interactions can produce large pressure oscillations within the combustor and can reduce component life and potentially lead to premature mechanical failures. Active Combustion Control which consists of feedback-based control of the fuel-air mixing process can provide an approach to achieving acceptable combustor dynamic behavior while minimizing emissions, and thus can provide flexibility during the combustor design process. NASA's Active Combustion Control activity aims to demonstrate active control in a realistic environment relevant to aircraft engines by providing experiments tied to aircraft gas turbine combustors. The intent is to allow the technology maturity of active combustion control to advance to eventual demonstration in an engine environment. 
NASA Glenn Research Center's prior activity has demonstrated active control to suppress a highfrequency combustion instability in a combustor rig designed to emulate an actual aircraft engine instability experience with a conventional rich-front-end combustor. NASA's current effort is developing further understanding of the problem specifically as applied to future lean-burning, very low-emissions combustors. A prototype advanced, low-emissions aircraft engine combustor with a combustion instability has been identified and previous work has characterized the dynamic behavior of that combustor prototype. The combustor exhibits thermoacoustic instabilities that are related to increasing fuel flow and that potentially prevent full-power operation. A simplified, non-linear oscillator model and a more physics-based sectored 1-D dynamic model have been developed to capture the combustor prototype's instability behavior. Utilizing these models, the NASA Adaptive Sliding Phasor Average Control (ASPAC) instability control method has been updated for the low-emissions combustor prototype.

Active combustion instability suppression using the ASPAC control method has been demonstrated experimentally with this combustor prototype in a NASA combustion test cell operating at engine pressures, temperatures, and flows (Ref. 8). A high-frequency fuel valve was utilized to perturb the combustor main fuel flow. Successful instability suppression was shown using a semi-infinite-line dynamic pressure sensor in the combustor for controller feedback. Instability control was also shown with a pressure feedback sensor in the lower temperature region upstream of the combustor. Further, it was demonstrated that the controller can anticipate and prevent the instability from growing while the combustor operation was transitioning from a stable, low-power condition to a normally unstable highpower condition, thus enabling the high-power condition (see Figure 7).
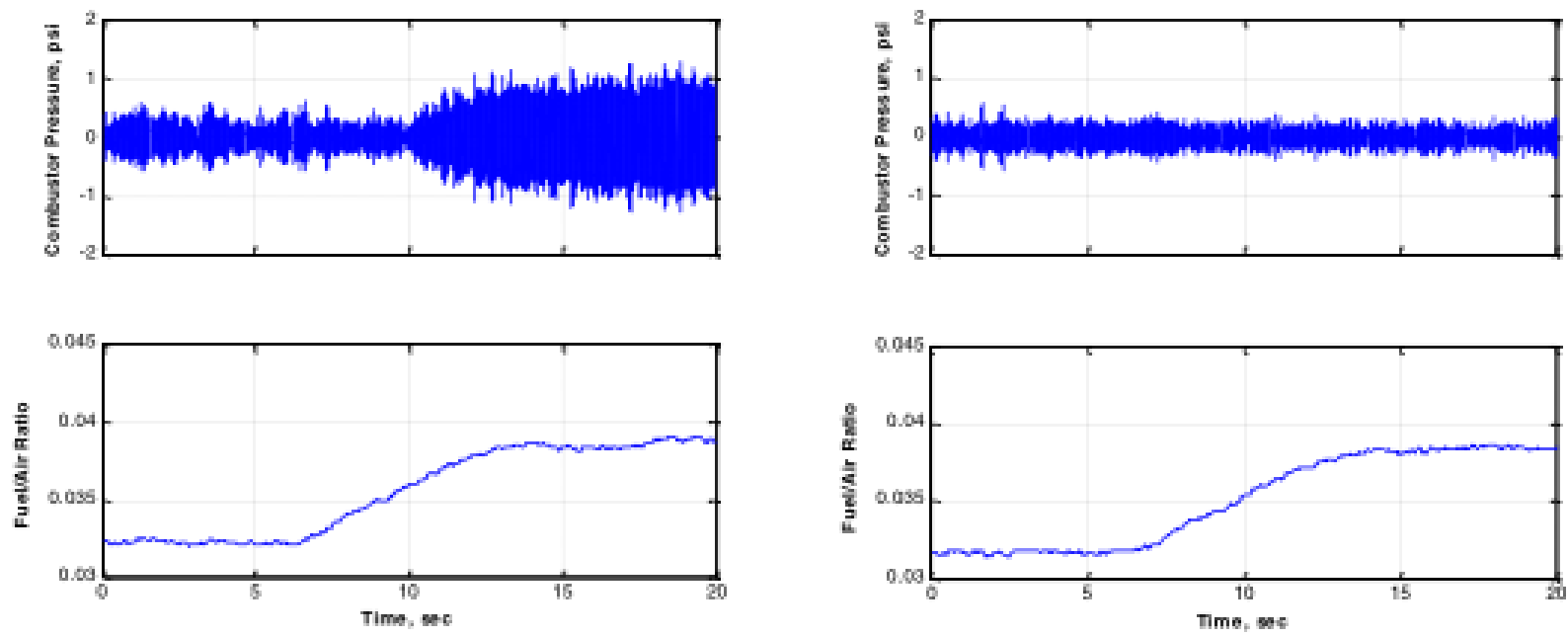

a) Without APSAC Control

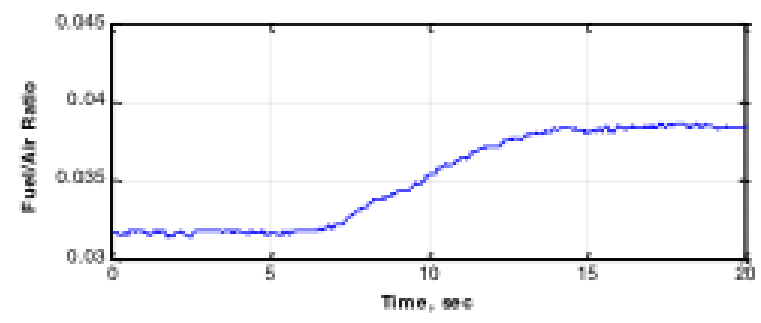

a) With APSAC Control Active

Figure 7: Growth of the combustion thermoacoustic instability is prevented by application fo the APSAC closed-loop control during an increase in fuel air ratio. Shown above are combustor rig experimental data for the fuel air ratio and the combustor pressure. Refer to Ref 8.

Future work is planned to further mature the combustion instability control technologies for application to more advanced low-emissions combustor concepts. The ASPAC control method is being adapted for these advanced combustors. Pressure sensors are being developed for controller feedback that can operate un-cooled up to $600{ }^{\circ} \mathrm{C}$ in the regions close to the combustor. 
High-frequency fuel modulation devices are being developed that can perturb the fuel through much smaller fuel injectors such as pilot fuel injectors or those encountered in lean, multi-point fuel injectors. The goal of these efforts is to integrate and demonstrate these technologies to enable stable, full-envelope operation of future lean-burn, low-emissions combustors.

\section{Propulsor Technology}

The goal is to develop and demonstrate an Integrated Propulsor to meet $42 \mathrm{~dB}$ noise reduction below the ICAO stage 4 regulations while achieving 50 percent reduction in fuel burned. Ducted, unducted and embedded ultra high bypass propulsor systems are being investigated. Advanced ultra-high-bypass ratio propulsors are attractive to provide increased propulsive efficiency and reduced fan \& jet noise to meet the ERA goals at the expense of increased nacelle weight and drag for ducted propulsors (refer to Figure 8 and Ref. 9). Open rotor systems optimize propulsive efficiency with ultimate bypass ratio and low fan pressure ratio but lack nacelle liners thereby resulting in less noise suppression than ducted systems. Embedded, boundary layer ingesting propulsors have the potential to realize increased propulsive efficiencies and noise levels below those of both ducted propulsors, but require additional development of advanced technologies and vehicle integration. Propulsion system fuel burn \& noise reduction, in combination with airframe technologies, will be required to achieve the ERA goals. Unfortunately most noise reduction efforts compromise performance and similarly propulsion performance enhancements to reduce fuel burn also impact noise. Therefore, the technical challenge for the Low Noise, High Efficiency Propulsor System is: Demonstrate the technologies to develop an integrated propulsor to meet $42 \mathrm{~dB}$ noise reduction below ICAO stage 4 regulations while achieving $50 \%$ percent reduction in fuel burned at the aircraft system level, without penalties in stability and durability of the engine system. To address these challenges the approach is to study the trade space between fuel burn and noise reduction by assessing ducted, embedded, and unducted propulsor systems. Specific technologies being pursued include: 1) Advanced low-noise open rotor systems, 2) Integrated UHB fan, low weight nacelle systems, with advanced noise reduction technologies such as OTR (Over-The-Rotor) liners \& soft vane technology, and 3) Efficient, stable, embedded high bypass engine systems that are integrated with the vehicle to reduce vehicle drag without penalizing the fan performance or operability.

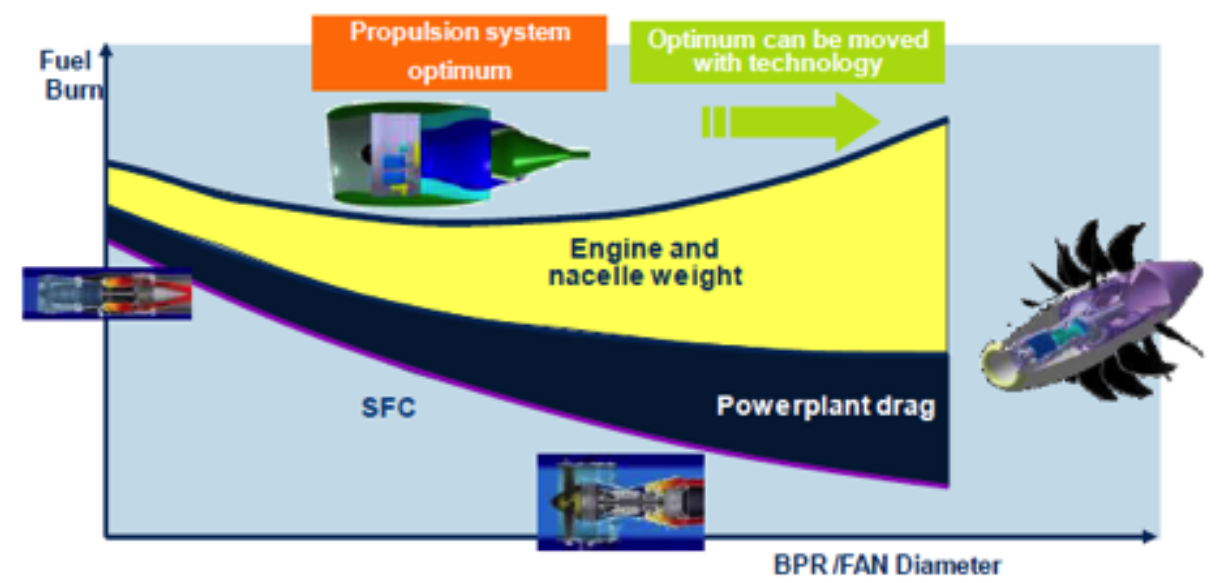

Figure 8: Impact of Bypass Ratio on Fuel burn and engine weight (Ref. 9). 


\section{A. Open Rotor: Discussion \& Results}

The open rotor research effort sets out to explore the design space for lower noise while maintaining the high propulsive efficiency from a counter-rotating open rotor system which has already been demonstrated to provide $20+\%$ reductions in fuel burn relative to a turbofan with a bypass ratio on the order of 5-7. The approach is to collaborate with General Electric (GE) and CFM International, a 50/50 joint company between Snecma and GE General Electric and CFM International to evaluate low noise blade designs. Additional partnering with GE and the FAA/CLEEN program has been employed to evaluate second-generation advanced open rotor blade sets designed to minimize noise and improve efficiency and look at pylon and installation effects. To assess the designs, tests will be performed in both the NASA 9x15 wind tunnel to measure noise and in the 8x6 transonic wind tunnel to validate performance. CFD provides comparative analysis and advanced laser diagnostics are incorporated into the experiment in order to understand the flow physics and improve the open rotor designs.

The following Open rotor configurations in Table 2 have been tested in the NASA 8x6 and 9x15 wind tunnels from October 2009 - January 2012. Figure 9 shows the open rotor installed in the 9x15 Low Speed Wind Tunnel and the $8 \times 6$ high-speed wind tunnel.

\begin{tabular}{|c|c|}
\hline Gen-1 Blade Sets (NASA/GE) & Gen-2 Blade Sets (NASA/FAA/GE) \\
\hline Historical Baseline blade set & 6 GE Advanced Designs \\
\hline Modern Baseline blade set & Pylon wake mitigation \\
\hline 2 GE Advanced Designs & \\
\hline 2 Snecma Designs & \\
\hline
\end{tabular}

Table 2: Open Rotor Configurations Tested at NASA GRC Wind Tunnels.

The Open rotor test results are summarized below and details can be found in Refs. 10-16:

1. Testing on the GEN I blade set, including Laser diagnostics, in the NASA 9x15 was completed in October of 2010. The Gen-1 blade designs have demonstrated acoustic margin to Chapter $(\mathrm{CH}) 4$ that is equivalent to some contemporary tube-and-wing aircraft with turbofan engines - see Figure 10.

2. The NASA systems analysis team has developed a model to analyze a modern open rotor based propulsion system on a modern airframe. NASA system level assessments estimate a $25+\%$ fuel burn and $15+$ EPNdB stage 4 noise margin - see Figure 11.

3. The Gen 1 and Gen 2 high speed Open Rotor testing in the NASA GRC 8x6 was completed on 9/9/2011. Gen 2 testing is a collaboration of FAA/CLEEN, GE, and NASA.

4. Gen 2 testing in the NASA 9x15 wind tunnel including multiple blade sets and integrated pylon tests. All testing was complete Jan 19, 2012. The Gen-2 blade designs offer the promise of additional acoustic margin. Analysis and documentation of the data is in progress and expected to be completed over the next year.

Although these open rotor result show promise, more research on installation effects and certifications must be addressed before open rotor propulsion systems are installed on commercial aircraft. Also, it is unlikely that Open Rotor systems will be able to match the acoustic margin of ducted systems because Open Rotor systems by definition have no duct (and acoustic liner) and, as a result, have greater flow and acoustic interactions with the airframe. In the next section we will discuss the challenges of an ultra high-bypass ducted propulsor. 

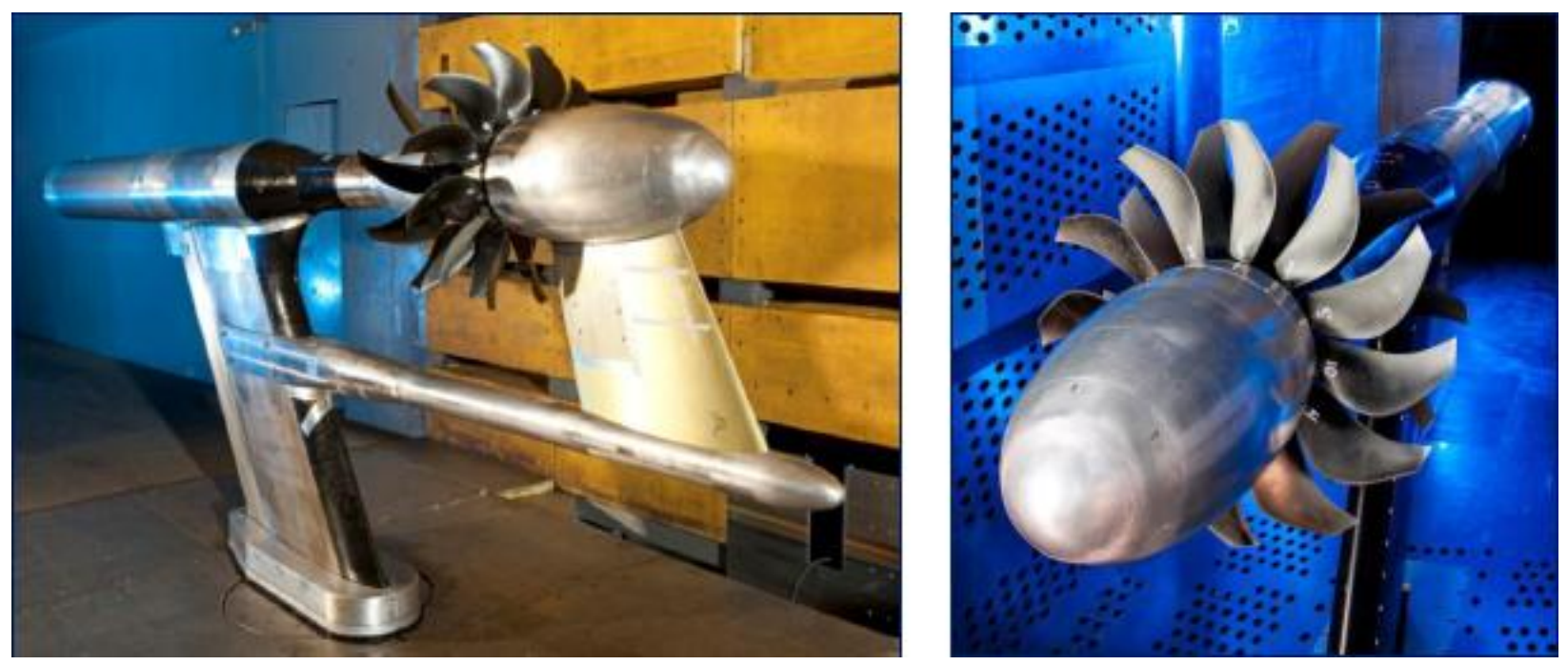

Figure 9: The Open Rotor Propulsion Rig installed in the 9x15 Low Speed wind tunnel on the left and on the right it is installed in the 8x6 Transonic Wind Tunnel in preparation for performance testing at cruise Mach of $\sim 0.8$.

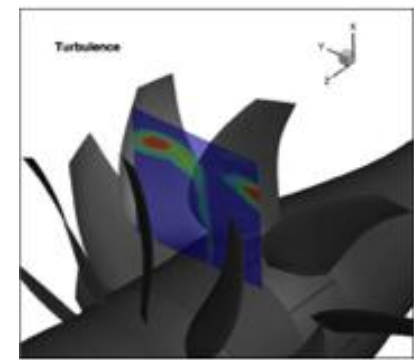

The 3D PIV measurements provide a wealth of information about the blade wakes and vortex track.

The location of peak noise level in the phased array map changes in the presence of the CFMI pylon indicating a change in the relative strength of sources.

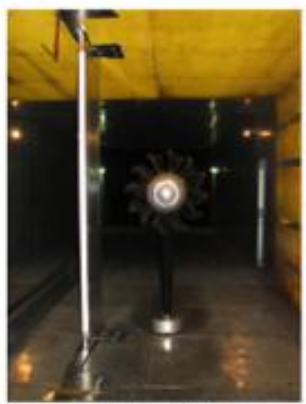

A canonical shielding configuration provides code validation data.

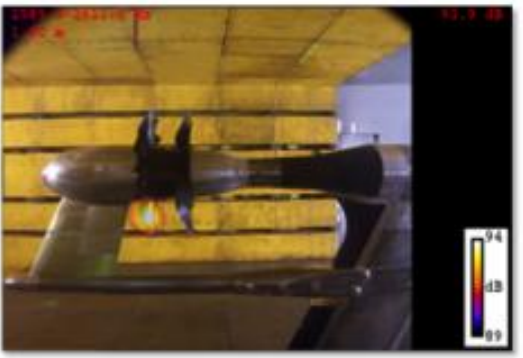

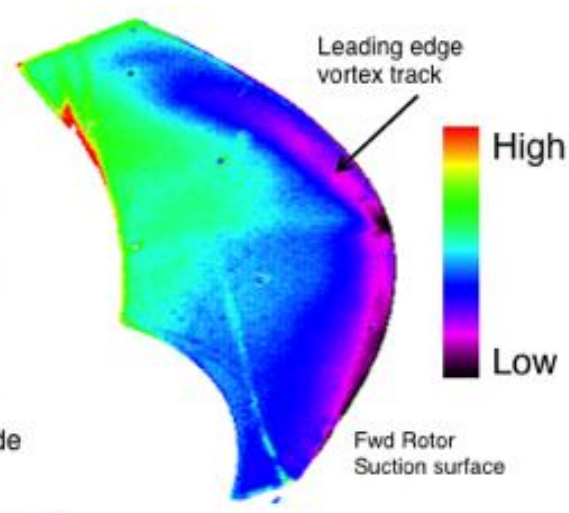

The Pressure Sensitive Paint measurements show phase locked static pressure on the surface of the rotating blade.

Figure 10: Sampling of detailed historical baseline flow field measurements. 


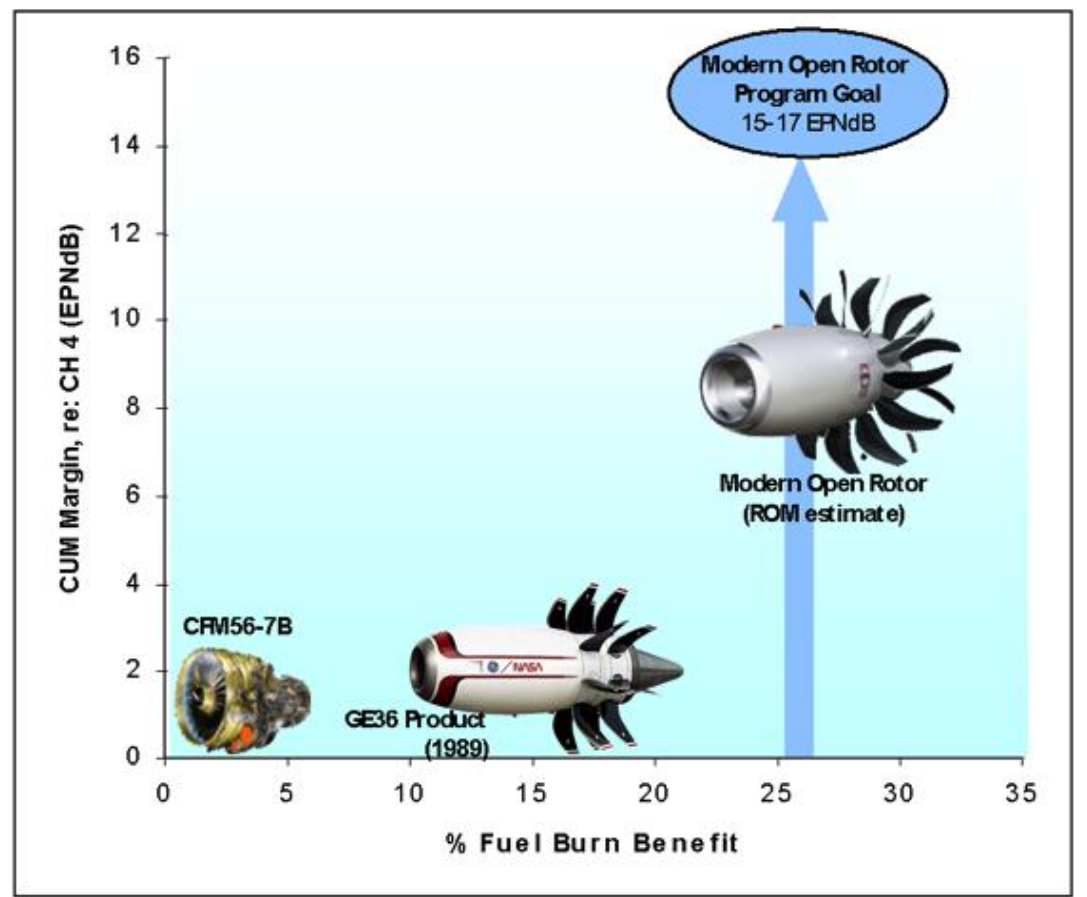

Figure 11: Modern Open Rotor design estimates are consistent with NASA system level assessments indicating greater than 25\% reduction in fuel burn and about 15 EPNdB noise margin to Chapter 4.

\section{B. Ultra-High Bypass / Geared Turbofan: Status \& Results}

The direction of turbofan technology has been moving toward higher engine bypass ratios (BPR) and lower fan pressure ratios (FPR). Figure 12 illustrates the trend in fuel burn with BPR and FPR. As the BPR increases and the corresponding FPR decreases, the amount of fuel burned decreases. However, there is a downside to continuing to decrease the FPR and increase the BPR, which is the fan diameter must get larger to produce that same amount of thrust. A larger fan also means a larger engine nacelle diameter, creating additional drag at higher flight speed conditions, meaning more thrust is needed to overcome the higher drag. One other aspect affecting high bypass ratio designs is engine core size. Since noise is also a consideration in high bypass fan designs, fan speed must be kept as low as possible to reduce its noise signature. However, lower fan speeds mean lower compressor and turbine component speeds in the engine core as well, since a common drive shaft connects the core components and the fan. A specific amount of power is needed to drive the fan for a given thrust, and so as the fan design speed drops so the core components must get larger in size, both in number of stages and in stage diameter, to provide the needed power since the core component speeds cannot increase. Larger components mean more weight, and more fuel burn to carry that weight around. Aircraft system design studies for two different types of aircraft configurations are given in Refs. 3-5, which illustrates the impact of different engine cycles on aircraft performance. The result of these design constraints is shown in the fuel burn trend line in red in Figure 12. This shows that a practical limit is finally reached as the trend line reaches a low point and then turns up again as the fan size increases, meaning more fuel burned. Beyond this point, the added weight and drag of a larger fan and nacelle, plus the increase in core weight overcomes the fuel advantage of the higher BPR and lower FPR design. What is needed is a paradigm shift in propulsion technology to extend the fuel burn advantage trend line with increasing BPR which is the objective of the NASA ERA propulsion technology development efforts (Refs. 17-22). 


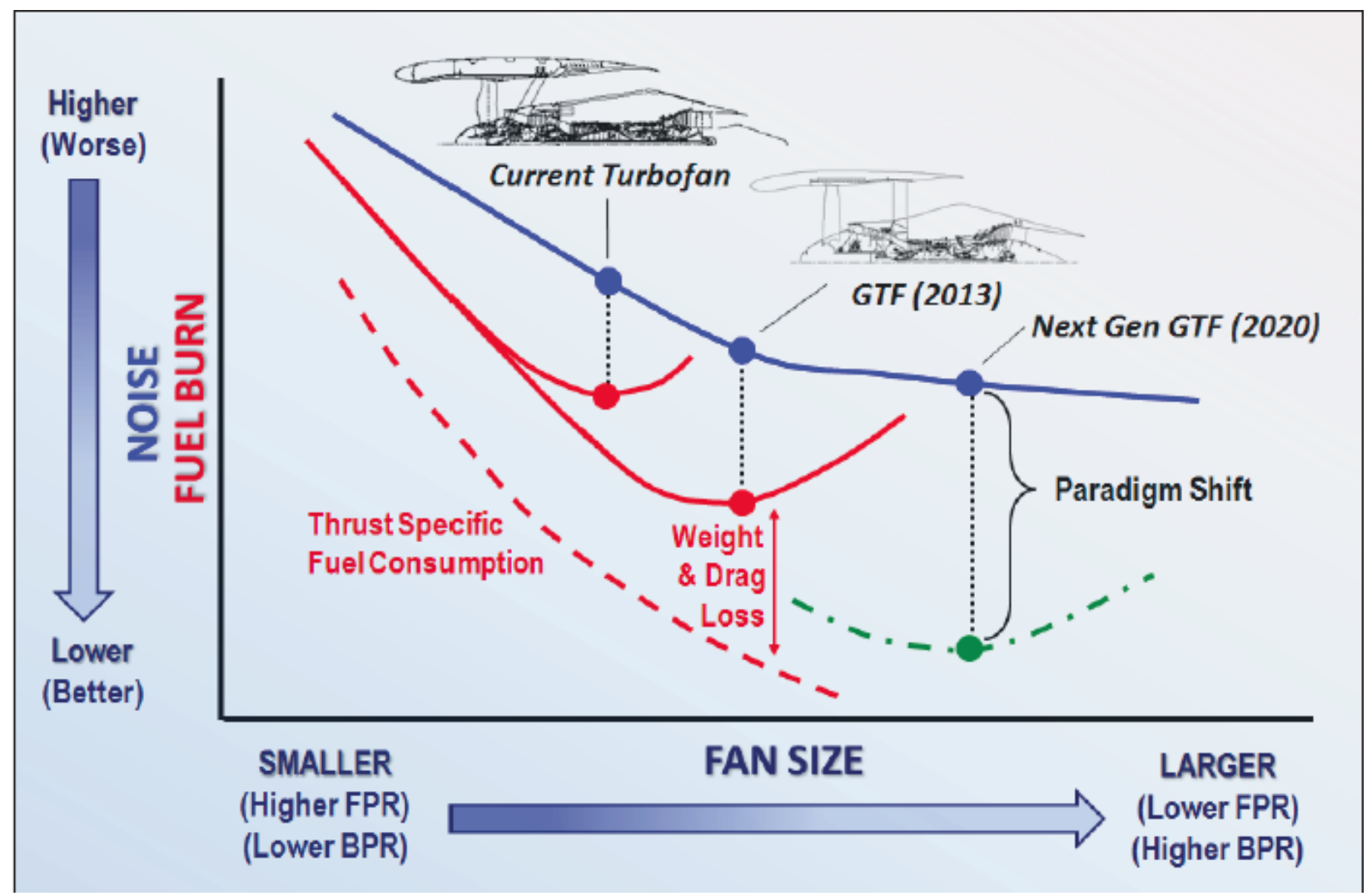

Figure 12: Effect of fan size, bypass ratio, and fan pressure ratio on fuel burn.

The objectives are to investigate aerodynamic performance, operability, and noise characteristics of $2^{\text {nd }}$ Gen Pratt \& Whitney (P\&W) Geared TurboFan technology for both conventional and advanced nacelles with lower weight and drag, and to develop and demonstrate advanced noise reduction technologies for Ultra High Bypass engine cycles.

The approach is to collaborate with $\mathrm{P} \& \mathrm{~W}$ to design and test a scaled $2^{\text {nd }}$ Gen Geared TurboFan and develop and demonstrate NASA noise reduction technologies. Rig hardware will include a configuration for aerodynamic testing to map performance and operability as well as a configuration to measure acoustics. Parametric studies will be performed using conventional and advanced low weight, low drag nacelles and fan/vane configurations. Furthermore, a specific focus will be to design $2^{\text {nd }}$ Gen Over-the- Rotor (OTR) and Soft Vane (SV) acoustic treatments for a heritage 1.5 pressure ratio fan model and test in NASA GRC 9'x15' LSWT to assess the impact on noise and performance - see Figure 13.

A summary of the accomplishments to date include:

- P\&W fan model final design was completed and model hardware was delivered to NASA GRC in March 2012.

- NASA UHB Drive Rig refurbishment completed; new onboard, 48-channel, digital telemetry data system and six-component rotating force balance were incorporated to actively monitor and accurately measure fan model characteristics with highly distorted inflow at angle of attack - see Figure 14.

- Testing of OTR/SV acoustic noise reduction concepts in the NASA Langley Research Center (LaRC) impedance facilities was completed and the data was used to validate the LaRC liner design code; final acoustic design of advanced OTR and SV acoustic liners was completed and fabrication is underway. 
- A risk mitigation test of OTR acoustic liner using a heritage fan in the NASA W8 single stage compressor facility was successfully completed on June 20, 2012. The goal was to verify the impact of the OTR rub strip on fan aerodynamic performance. Pretest CFD predictions indicated a $1 \%$ loss in adiabatic efficiency at the fan design point. Results from the test showed efficiency loss from $1.5 \%$ at approach to $0.75 \%$ at max fan speed tested, which was $90 \%$ of fan design speed. This loss is considered acceptable and development of the OTR rub strip for testing in the GRC 9'x15' wind tunnel in December of 2012 will continue.

- Check out run of the drive rig and instrumentation with the P\&W GTF $2^{\text {nd }}$ Generation fan model installed in the 9x15 wind tunnel was successfully completed on June 28, 2012. The goal was to verify the structural integrity of the fan and the operation of the newly rebuilt UHB Drive Rig prior to a labwide maintenance shutdown starting in July and extending into early September of 2012.

- The 2nd Generation Pratt \& Whitney Geared Turbofan test hardware was installed in the 9x15 to investigate the effect of highly distorted inflow at angle of attack on aerodynamic performance, operability and structural response, and noise for advanced inlet, fan, and stator designs; comprehensive array of pressure, temperature, unsteady pressure, and hot film anemometry measurements are being acquired. Results to date have validated both 1) the blade aeromechanical performance is consistent with advanced CFD predictions over a wide range of angle of attack/crosswind conditions, and 2) improved efficiency inlet aero performance is consistent with advanced CFD predictions over a wide range of angle of attack/crosswind conditions. The plan is to complete the aerodynamic data acquisition in 2012 and acquire all of the noise data in the early weeks of 2013. The data acquired to date is in agreement with the pre-test predictions in terms of both stability and performance.
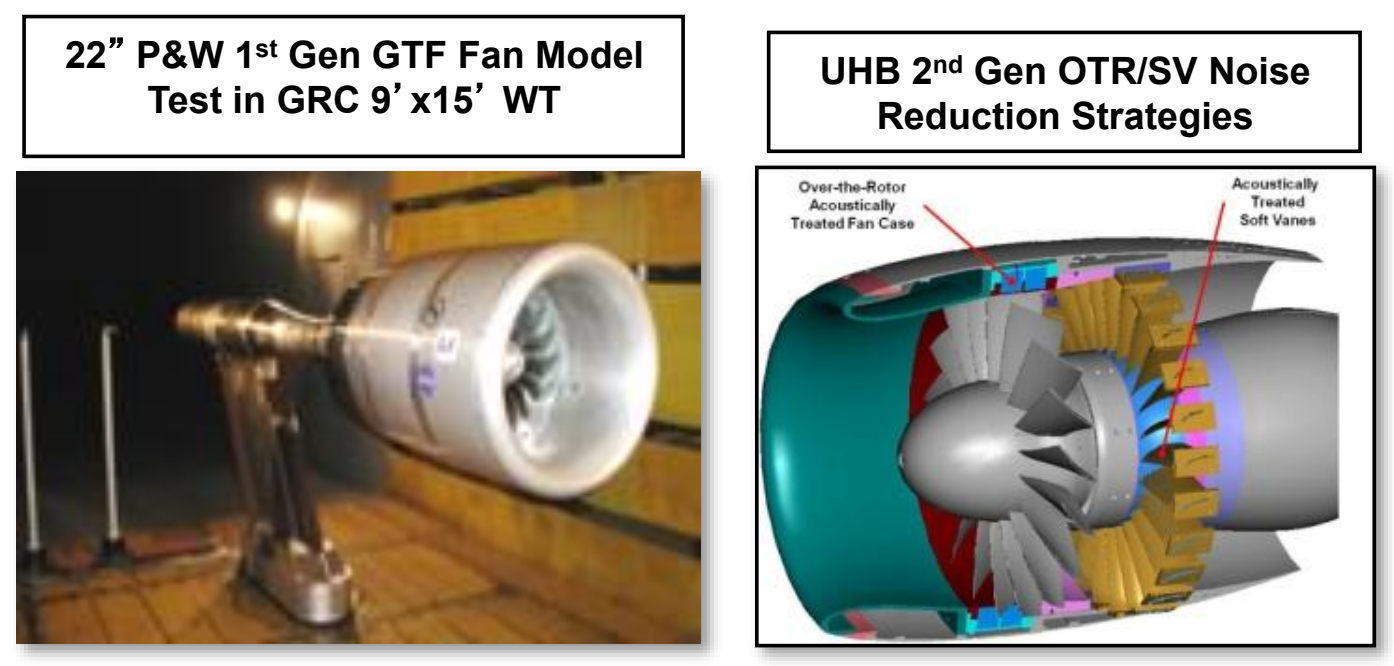

Figure 13: (a) P\&W Geared TurboFan installed in the 9x15 low speed wind tunnel. (b) Over-the-Rotor and Soft Vane noise reduction technologies. 


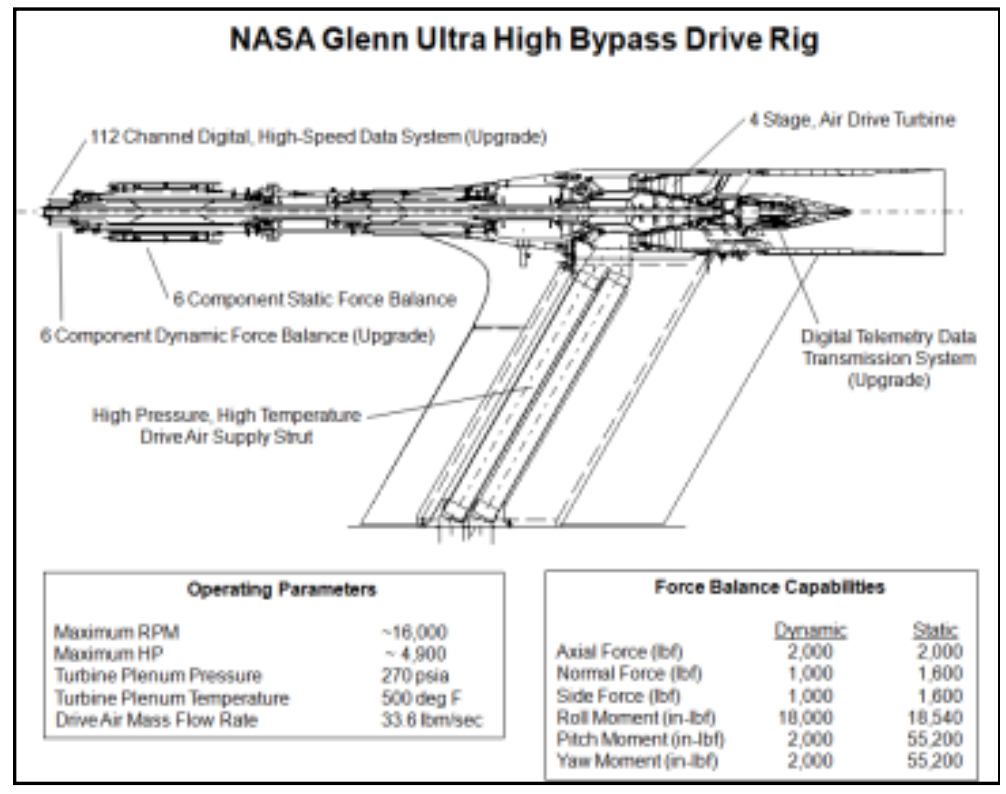

Figure 14: Refurbished UHB drive rig with 6 component balance and new telemetry system.

\section{Embedded Fan-Propulsor: Status \& Results}

The embedded inlet fan-propulsor effort is being worked in collaboration between the NASA ERA Project and the Fundamental Aero Program's (FAP) Fixed Wing (FW) project. The embedded inlet fan-propulsor activity aims to achieve increases in aircraft fuel efficiency (drag reduction) by ingesting a substantial portion of the fuselage boundary layer into its engines. This is to be done by embedded propulsor systems that integrate a boundary layer ingesting (BLI) inlet and a distortion-tolerant fan design intended to minimize the impact of the boundary layer flow on fan performance and stability margin (Refs 23-35). The goal is to demonstrate an embedded integrated inlet and distortion-tolerant fan system that provides the identified aircraft benefits by achieving less than a $2 \%$ loss in fan efficiency while maintaining ample stability margin. The approach is to: 1 ) use an existing FAP FW-sponsored NASA Research Announcement (NRA) blended wing body design such as is depicted in Figure 15, to define the design constraints for the inlet boundary layer and the requirements for a relevant embedded engine configuration, 2) partner with United Technologies Research Center (UTRC), Pratt \& Whitney $(\mathrm{P} \& W)$ Aircraft Engines and Virginia Polytechnic and State University (Virginia Tech) through the NRA to exploit the optimal design space and design and build an integrated inlet/fan embedded system, and 3) verify the design with computational analysis and a wind tunnel experiment in NASA's 8'x6' transonic wind tunnel. The design verification will be conducted by the FW project inclusive of substantial engineering design and fabrication support provided by the ERA project. The arrangement of this embedded propulsor experiment is shown in Figure 16.

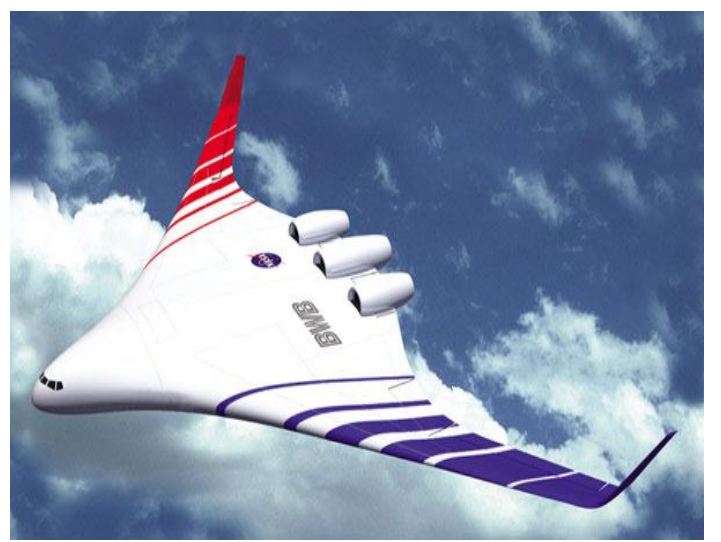

Figure 15: Reference blended wing body aircraft with embedded ultra high bypass ratio turbofan engines. 


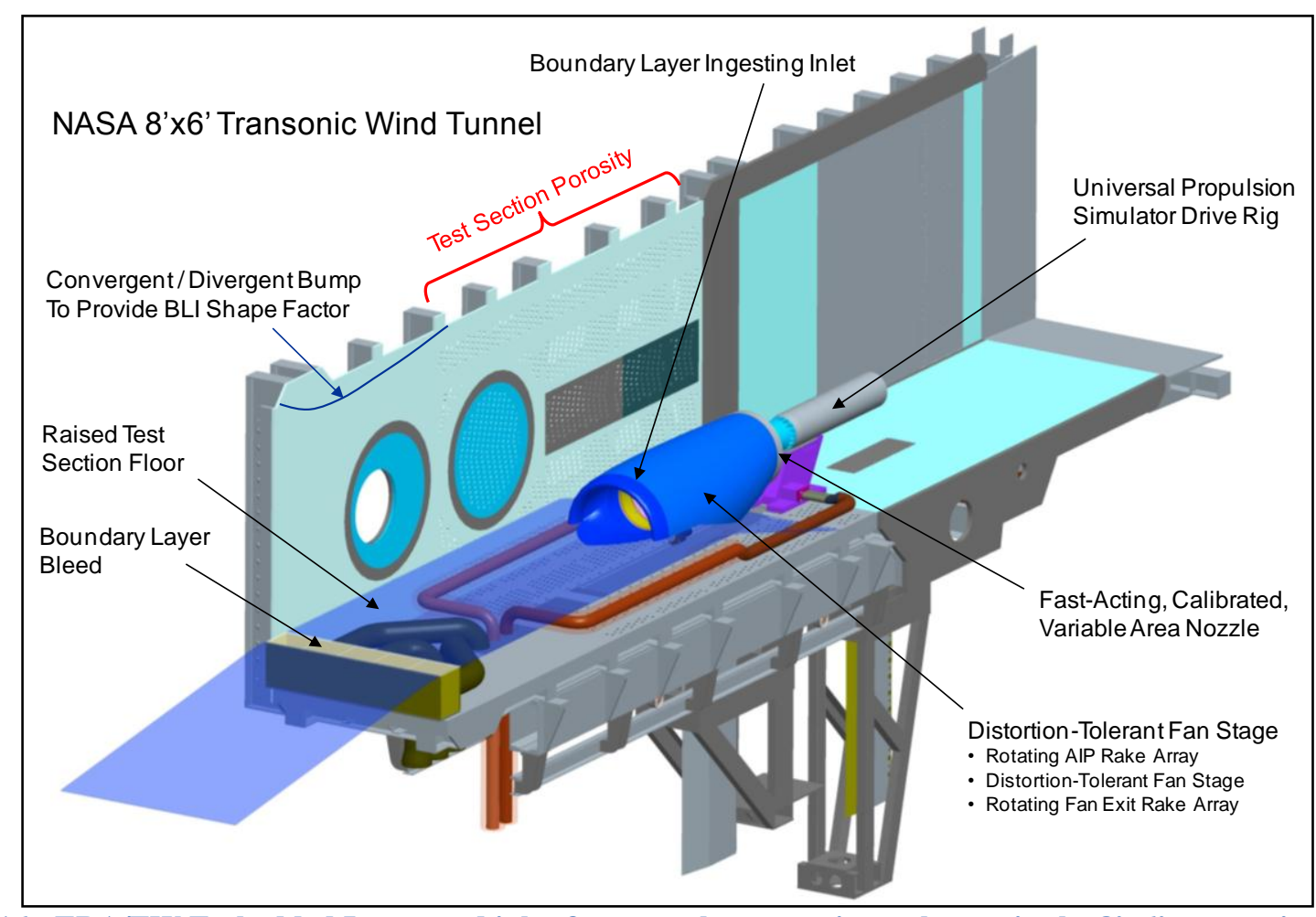

Figure 16: ERA/FW Embedded Integrated inlet-fan propulsor experiment layout in the 8' 6' $^{\text {' transonic wind }}$ tunnel.

To date, UTRC has completed the aerodynamic design of the integrated BLI inlet and distortion-tolerant fan stage. Virginia Tech has completed foundtional experiments into the impact of BLI distortion on a turbofan engine. NASA has completed much of the aerodynamic and mechanical design of the remainder of the experiment (e.g. raised floor, boundary layer bleed system, drive rig modifications, variable nozzle, etc) to support the tests in the NASA 8'x6' facility. Due to unavailability of the 8'x6' wind tunnel and the complexity of the integrating the inlet and fan hardware with the remainder of the experiment, testing is not planned until FY 2014. Computational results obtained from UTRC indicate that the design will incur less than a $1 \%$ loss in fan performance. An overview of this collaborative research effort as well as results obtained to date has been reported in References 23 and 24-35, respectively.

\section{Core Technology}

In Figure 17 the relationship between cores thermal, propulsive, and overall efficiencies are outlined. It is evident from this figure that in order to make improvements in overall efficiency both propulsive and thermal efficiency must be improved. In the previous section the areas of research and development underway to improve propulsive efficiency were described. In this section the areas of ERA research and development to improve thermal efficiency will be presented. 


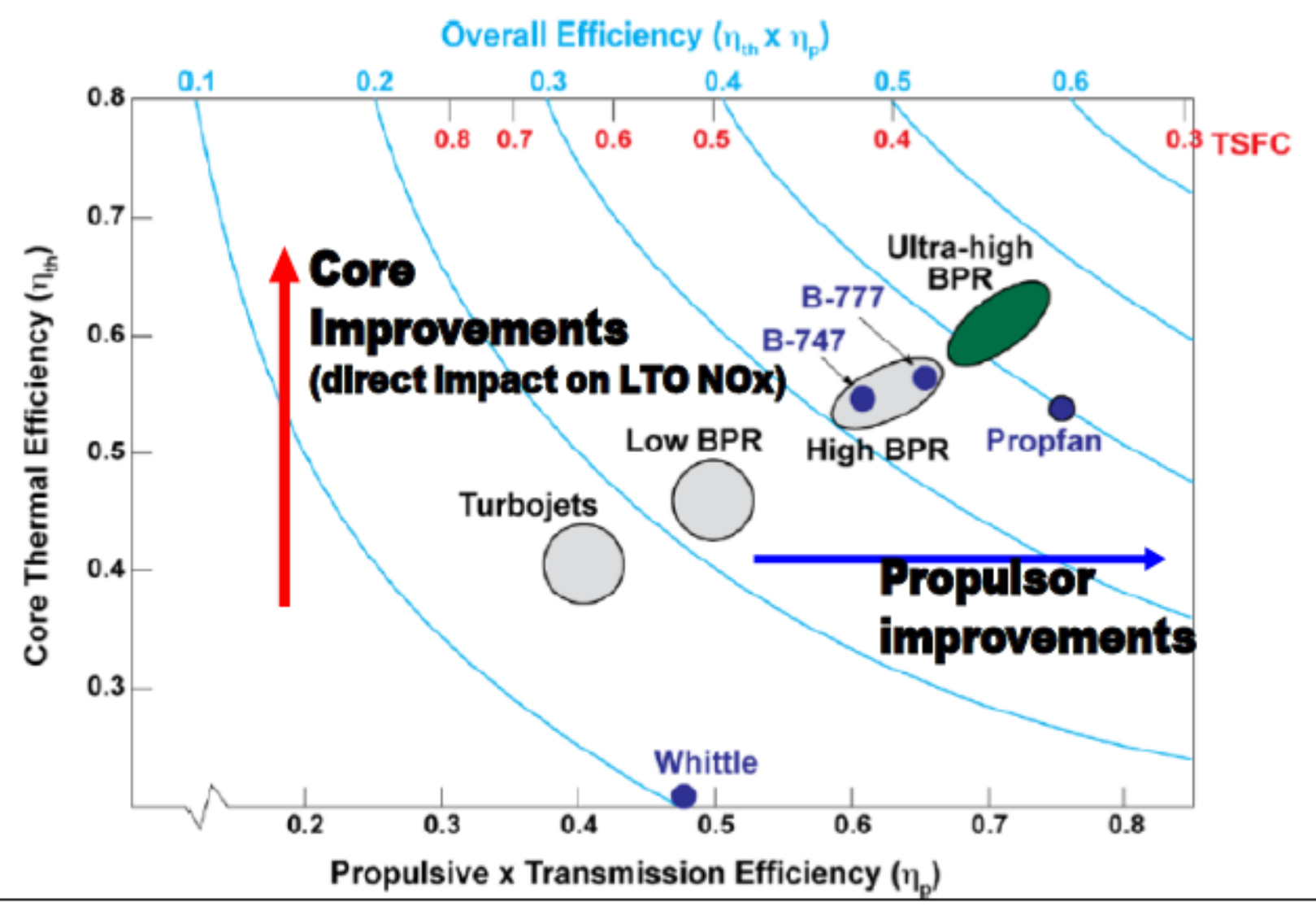

Figure 17: Tends in overall propulsion efficiency and thrust specific fuel consumption with core and propulsor improvements. Future improvements require increases in both thermal and propulsive efficiency.

The ERA goal is a 50\% reduction in fuel burn below current technology aircraft, while achieving a $75 \%$ reduction in LTO NOx below CAEP 6 requirements. Achieving this goal requires development of high power density, high thermal efficiency cores. High power density cores enable ultra-high bypass ratio systems by increasing bypass ratio with minimal changes in engine diameter required to achieve the higher bypass. Not only does this enable the UHB engines to be installed under the wing, but this also contributes to the reduce drag and weight associated with the larger diameter UHB engines. NASA system studies and studies performed by Georgia Tech ASDL under NASA contract show that the core engine and propulsor engine contribute equally to the fuel burn reductions predicted for the advanced engine in Figure 1. The technical challenges associated with high power density, highly efficient cores is that they result in 1) higher combustor inlet pressures and temperatures, which encourages NOx production, and 2) higher engine exhaust temperatures and jet velocities which increases noise and adds weight.

The approach is to: 1) Select NASA unique capabilities to increase thermal efficiency (fuel burn), minimize core diameter, and increase power density to enable high bypass ratio engines, 2) Maximize engine Overall Pressure Ratio (OPR) and turbine inlet temperature, T41, and reduce cooling flow and weight by: a) developing integrated Ceramic Matrix Composite (CMC) High Pressure Turbine (HPT) vanes and blades that are integrated with Environmental Barrier Coatings (EBC) and b) maximizing High Pressure Compressor (HPC) loading and performance, and c) develop and demonstrate low weight durable oxide nozzles, and 3) Interact with DOD to insure NASA unique capabilities in compression systems and EBC coatings are exploited. In the following sections the results will be divided into 2 elements: 1) one that addresses increase in engine overall pressure ratio by working on the compressor technologies, and 2) CMC material development to increase T41 and reduce cooling flow. The 
benefits of these technologies to reduce fuel burn are illustrated by the system study results shown in Figure 18 (Ref. 37).

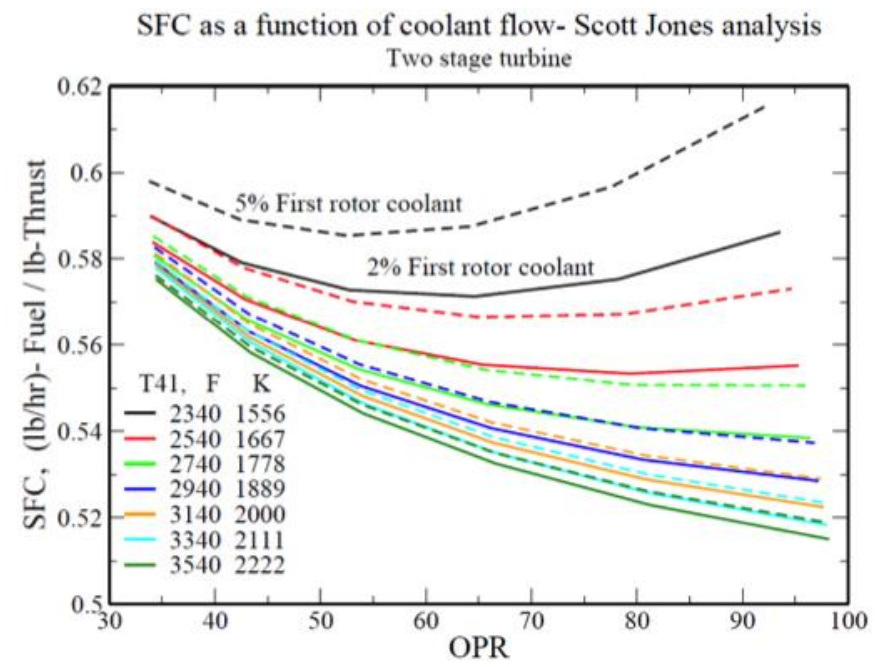

Figure 18: SFC reduction due to increased OPR and increased T4 as a function of reduced coolant flow.

\section{A. High OPR core Compressor Technology: Status \& Results}

The goals are to design and test the first two stages of a transonic state-of-the-art high pressure compressor in order to 1) understand the flow physics that limit stage loading, 2) characterize the interactions between the blade rows, and 3) validate the design methodology and capability of the prediction tools by comparisons with the experimental results. In order to meet the ERA goals from Table 1 it is essential to increase engine OPR and efficiency without negatively impacting weight, length, diameter, and operability.

To this end, NASA is collaborating with GE, via a cost share agreement, on the development and demonstration of a highly loaded front block core compressor. NASA will test the first two stages of an advanced GE Core Compressor using state-of-the-art research instrumentation to investigate the loss mechanisms and interaction effects of embedded transonic highly loaded compressor stages. The multistage test facility, W7 in the Engine Research Building (ERB) at NASA Glenn Research Center will be used to run this test. This facility is capable of running up to 18,756 RPM in both directions and can accurately measure mass flow to less than $1 \%$. The massflow range of this facility is $10 \mathrm{lbm} / \mathrm{sec}$ to $100 \mathrm{lbm} / \mathrm{sec}$ and can accommaodate a 20-22" diameter compressor with an overall pressure ratio of 9:1. GE is providing the advanced two-stage compressor rig and test support. See Figure $19 . \quad$ The test plan focuses on making steady and unsteady measurements for both the single stage alone and then subsequently after adding the $2^{\text {nd }}$ stage to enable evaluation of the performance and losses in each stage.

Results and status to date:

- The W7 facility driveline test was conducted during June 2012 testing. The driveline motor was operated up to $9000 \mathrm{rpm}$ (max capability of 20,000 rpm) but a vibration was detected in the gearbox and was diagnosed as an issue with the coupling between the gearbox and the compressor shaft. The vibration has since been corrected via modifications to the coupling installation.

- Validated bi-directional capability of the W7 facility motor drive, increased facility flow quality, and reduced measurement uncertainty in the W7 multistage compressor facility.

- System studies performed by GE have indicated that a 30\% increase in OPR relative to the GE90 would result in a $2-2.5 \%$ reduction in specific fuel consumption.

- The design and fabrication of a relevant compressor test rig to understand loss mechanisms and interaction effects of embedded transonic highly loaded compressor stages has been completed. GE delivered this compressor to GRC in October 2012.

- Pre-test CFD simulations have been completed. These results will be compared to experiments to determine breakout of stage $1 \& 2$ blade row interaction effects that limit stage loading and high OPR 
capability. The CFD pre-test predictions for the 2-stage pressure ratio and temperature ratio at $97 \%$ speedline are shown in Figure 20. The similarities between the fine mesh and coarse mesh solutions indicate the CFD simulations are not dependent on the mesh size. The details of the pre-test CFD are fully documented in Ref. 38.

- The GE compressor installation is underway and testing is expected to begin in March 2013.
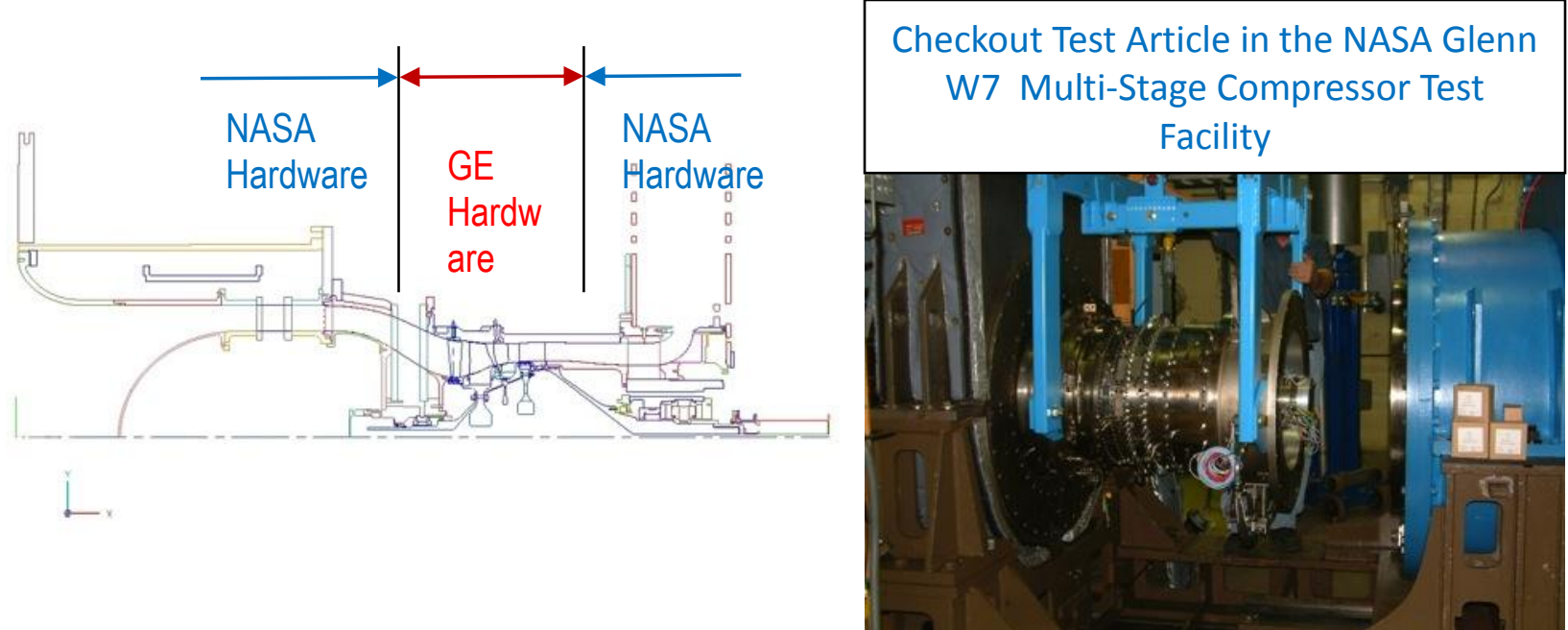

Figure 19: Checkout and integrated system test of the W7 multistage compressor facility.

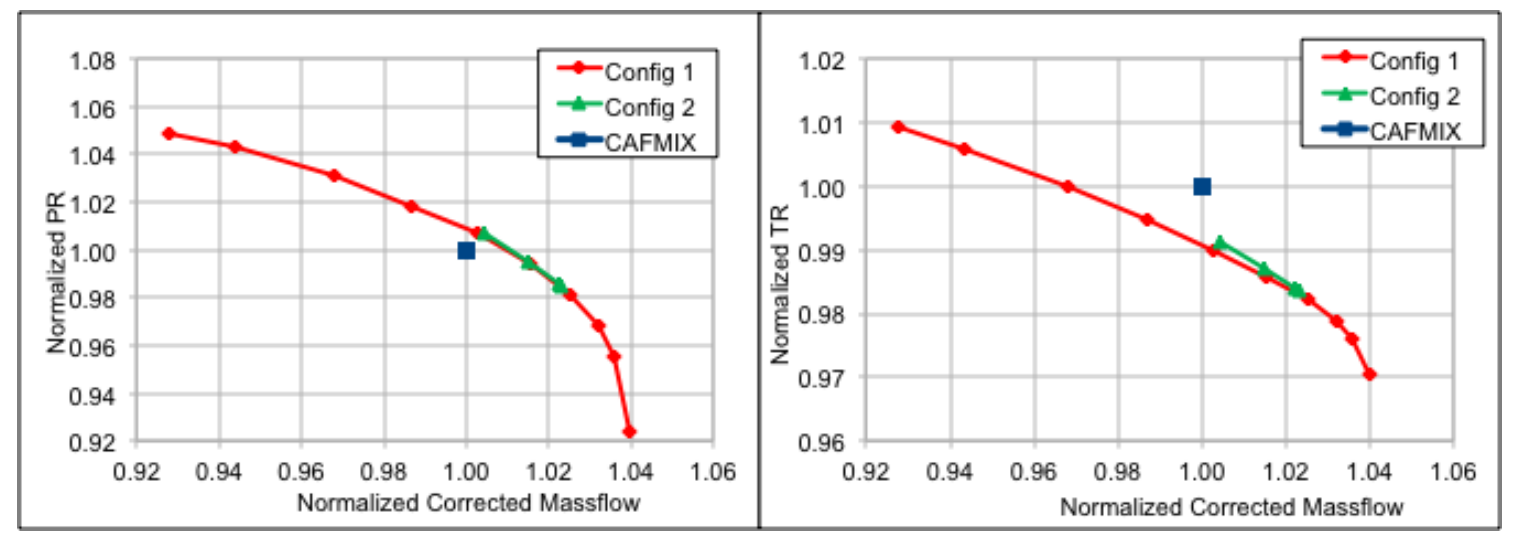

Figure 20: 2-Stage compressor data match results (CAFMIX) compared to the 97\% design speed line pre-test predictions using APNASA with a fine mesh (Config 2) and a coarser mesh (Config 1). See Ref 38 for details.

\section{B. CMC Technology: Status \& Results}

To help meet the goals of the ERA Project, three different types of CMC components are being matured. These include a CMC combustor liner, a CMC high pressure turbine vane, and CMC exhaust nozzles. Advanced environmental barrier coatings (EBCs) are also being developed for the $\mathrm{CMC}$ combustor liner and $\mathrm{CMC}$ vane. The primary objectives are to address manufacturability of the complex-shaped components and to evaluate/demonstrate component performance under engine operating conditions. Scale-up of manufacturing technologies toward fullscale component shapes will be pursued; followed by testing to verify component performance and durability in order to ensure that material properties are not significantly reduced compared to those of smaller-sized and well- 
characterized two-dimensional CMC panels. The major challenges to be addressed are in component fabrication, component cooling design, heat transfer characterization, test stand integration (CMC to metal attachments), and testing under relevant engine operating conditions.

The system level benefits of the CMC combustor liner are a 40\% reduction in cruise NOx and a $60 \%$ reduction in cooling air. The system level benefit for the CMC turbine vane is a 3-6\% reduction in fuel burn. Conventional CMC exhaust nozzles for large commercial aircraft offer a $20+\%$ reduction in component weight. CMC mixer nozzles for regional jets and business jets offer increased mixing efficiency through improved shape retention at operating temperatures.

The CMC components of interest are based on current state-of-the-art composite systems (Refs 39-42). For the combustor and vane tasks, the composite being utilized is silicon carbide ( $\mathrm{SiC}$ ) fiber reinforced silicon carbide matrix composite $(\mathrm{SiC} / \mathrm{SiC})$. With current commercial processing methods and the use of Hi-Nicalon type-S fiber, the components will have temperature capability up to $2400^{\circ} \mathrm{F}$. Through the use of advanced environmental barrier coatings (EBCs) that also perform as thermal barrier coatings, the vane and liner components will have surface temperature capability up to $2700^{\circ} \mathrm{F}$ (Refs $39-42$ ). The EBCs also provide reduced erosion rates to enhance durability and prolong component life. For the CMC exhaust nozzles, the composite of choice is an oxide fiber reinforced oxide matrix composite (oxide/oxide) that can operate at $1500^{\circ} \mathrm{F}$ for $80,000 \mathrm{hrs}$. That system does not require a protective coating to prevent oxidation due to the use of oxide constituents. Detailed

\section{CMC Turbine Vane}

Specifically for the CMC turbine vane development activity, the approach was to:

- Demonstrate fabricability of CMC's in simplified 3D vane shape using two or more processing methods

- Evaluate current state of the art materials in a relevant environment utilizing the high pressure burner rig at NASA GRC (see Figure 21).

- Test both flat panels and sections of simplified vane samples to compare as-fabricated properties of both to ascertain any degradation in material properties when going from a small coupon to a complex 3D shape.

- Evaluate coatings suitable for HPT environment - both commercial and NASA developed

- Perform a parametric trade study of key materials properties

- Identify key issues requiring further effort in Phase II

Simplified 3D vane shapes were processed using two different methods: 1) Hypertherm's Chemical Vapor Infiltration (CVI) and 2) GE's prepreg melt infiltration (MI) process. The melt infiltration method used a $0^{\circ} / 90^{\circ}$ unidirectional fiber layup while the CVI method incorporated five-harness satin weave cloth as the reinforcement phase. The fiber volume varied from approximately $21 \%$ for the MI samples to approximately $35 \%$ for the CVI materials. Both methods were used to fabricate flat panels and a simplified airfoil configuration (Figure 22). The panels were 6.0 " x 6.0 " with a thickness of 0.060 ". The simplified vane shapes were designed to incorporate some of the challenging processing features of the vane (such as the rib section, sharp trailing edge radius and varying wall thickness), but still allow for sectioning and testing of flat coupons. The objective was to make a direct comparison between the optimum properties which are typically measured with a flat panel to those found in the more challenging 3D components. The goal was to assess both processes for suitability when manufactured in a 3-D component and identify potential fabrication issues. Some of the comparisons between the Hypertherm CVI and GE MI materials are summarized in Ref. 41-42 and the highlights are below:

- NDE performed on composite panels identified no defects or internal damage.

- Initial characterization of Hyper-Therm CVI materials revealed significant increase in porosity of vanes compared to flat panels.

- NDE CT scans of vanes display large voids and delaminations (see Figure 22).

- Testing indicated both MI and CVI vanes showed losses in properties compared to their flat panel counterparts (see Figures 23 and 24). 
- The decrease in matrix density in CVI materials resulted in losses in matrix controlled properties, such as thermal conductivity and bend strength (see Figures 24 and 25).

- Low fiber volumes in MI composites combined with ply joints within the bend samples led to flexural strength losses in MI vanes (see Figure 23).

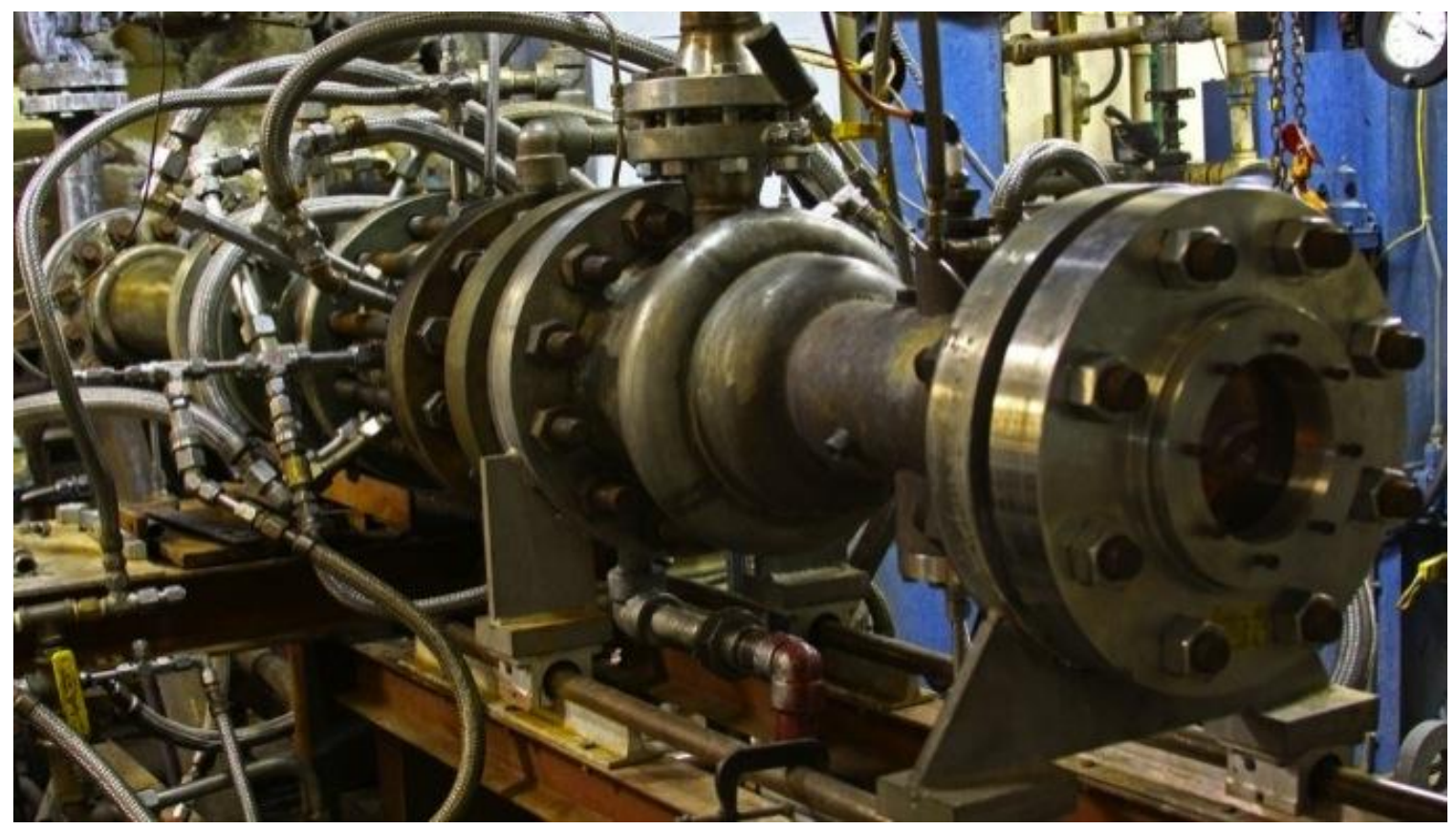

Turbinē specimen Burner nozzle

Combus̄tor specimen

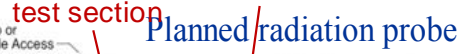
test section

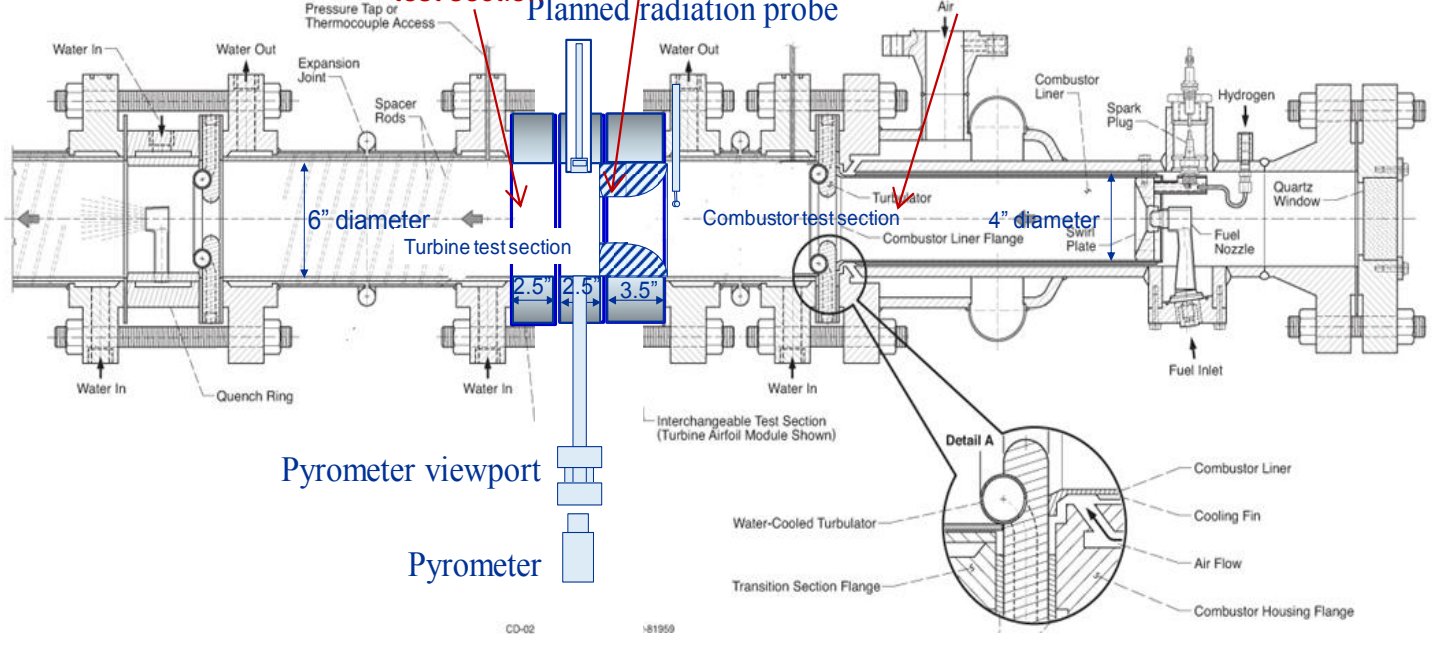

Figure 21: High Pressure Burner Rig (HPBR) simulates engine conditions up to 16 atm testing pressure, temperature capability $2600 \mathrm{~F}+$, and gas velocity up to $200 \mathrm{~m} / \mathrm{s}$. 


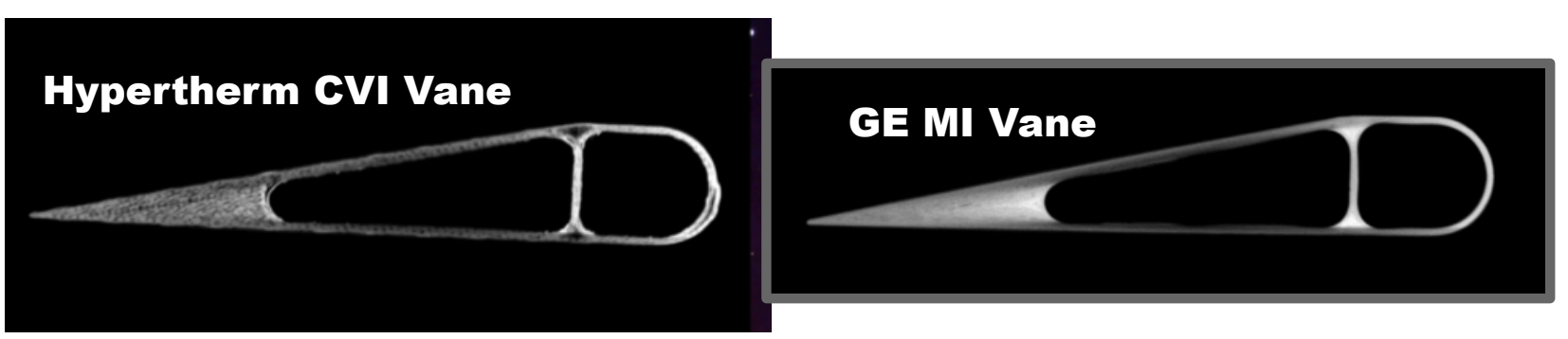

Figure 22: CT images of the Hypertherm CVI \& the GE MI vanes. Note the delamination in the Hypertherm vane.

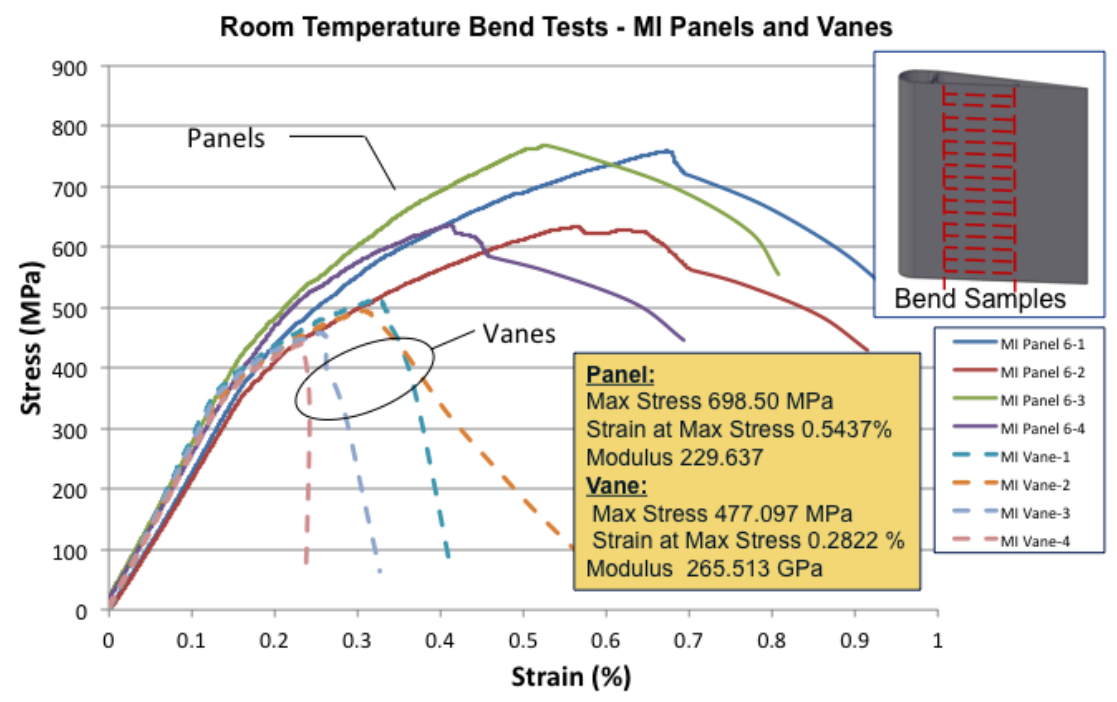

Figure 23: Comparison between mechanical properties of CMC 3D vanes and 2-D panels fabricated using the Melt Infiltration method

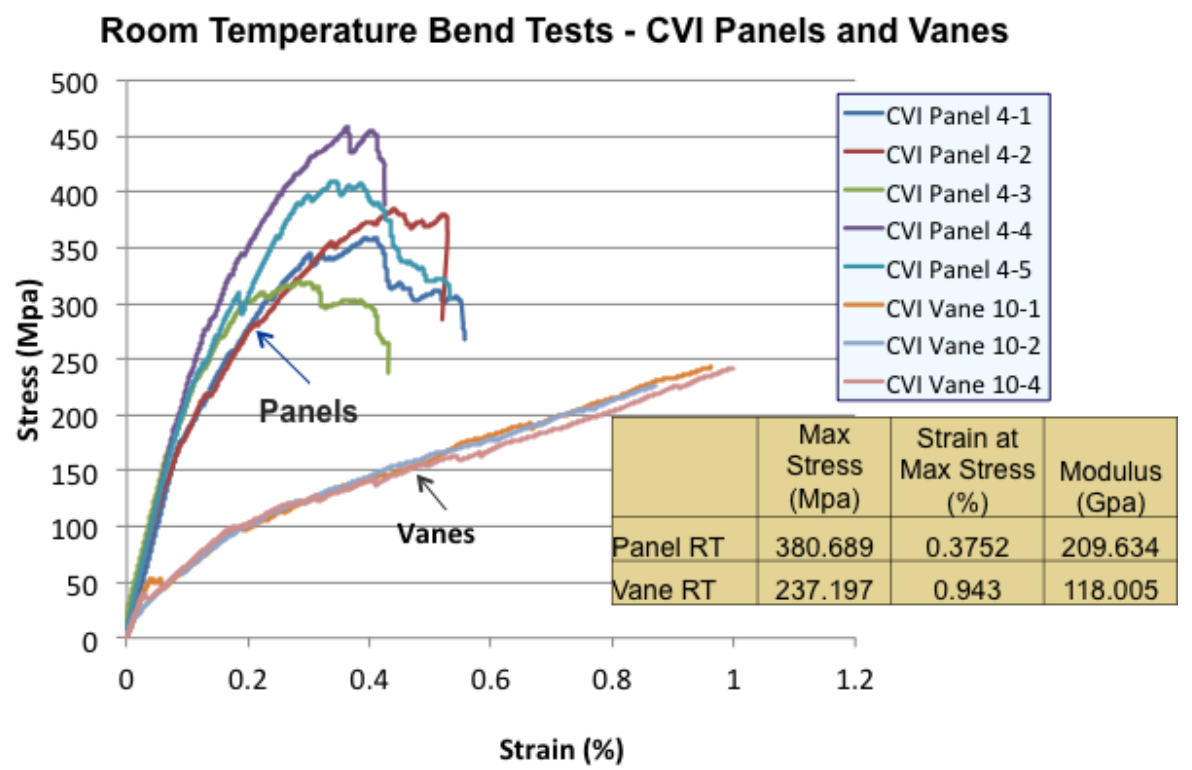

Figure 24: Comparison between mechanical properties of CMC 3D vanes and 2D panels fabricated using the Chemical Vapor Infiltration (CVI) Method

American Institute of Aeronautics and Astronautics 


\section{Thermal Conductivity of MI and CVI Panels and Vanes}

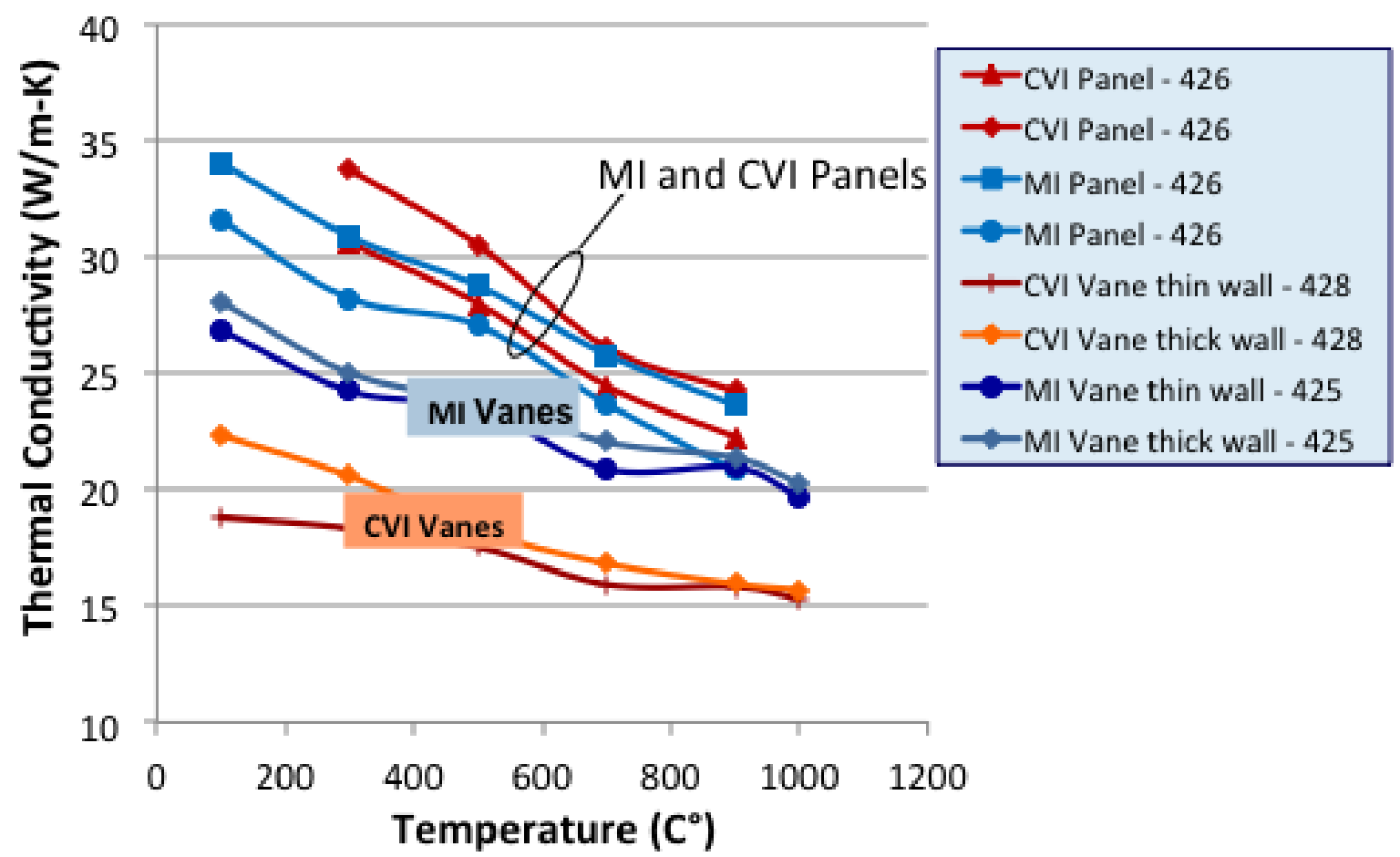

Figure 25: Thermal conductivity of MI and CVI panles and vanes measured by laser flash method, limited to $1000 \mathrm{C}$ test temperature.

\section{CMC Combustor Liner}

Similarly for the CMC liner development the key objectives were to investigate CMC combustor liner materials to enable new engine designs which incorporate higher engine temperatures and reduced cooling air flows, develop and validate CMC combustor liner material durability, and develop and validate advanced $2800 \mathrm{~F}$ environmental barrier coatings (EBCs) for $\mathrm{SiC} / \mathrm{SiC} \mathrm{CMC} \mathrm{combustor} \mathrm{applications.} \mathrm{In} \mathrm{addition,} \mathrm{through} \mathrm{collaborations} \mathrm{with}$ industry, a key objective is to evaluate the ability to fabricate and assess the durability of CMC liners.

The results to date include:

- The high pressure burner rig is up and running. The current standard high pressure testing condition has been achieved for film cooled recession tests: $16 \mathrm{~atm}$ testing pressure, temperature capability $2600 \mathrm{~F}+$, and gas velocity up to $200 \mathrm{~m} / \mathrm{s}$.

- Relative to CMC Integration into the Engine - the TiCrAlTaSiN based fretting resistant coatings testing was completed. The results showed optimized coatings had significant improvement in fretting wear resistance as compared to Haynes 230 combustor alloy.

- The Gen II CMC recession testing at $1300^{\circ} \mathrm{C}$ under impingement cooling condition was completed. The film-cooled recession was tested and is being modeled using CFD (see Figure 26). Note from this figure, the strong influence of velocity on the regression rate of the CMC.

- The film cooling CFD modeling work is in progress. The initial heat flux tests and the first 7-hole film cooling specimen (using 200F cooling air) test was completed.

- The first combustor EBC coated GE Prepreg SiC/SiC CMC tensile specimen completed heat flux tensile rupture testing, accumulating a total $370 \mathrm{hrs}$. of test time.

- Developed and demonstrated $2000^{\circ} \mathrm{F}$ fretting-wear integration environmental barrier coatings. 
- An inner and outer full-scale combustor liner has been fabricated and has been coated with an EBC.

- The durability testing (minimum of $50 \mathrm{hrs}$ ) of the full scale EBC liner will continue throughout December of 2012. Upon successful completion of this test, the fabrication ability of producing large CMC cylinders for combustor liner applications will be demonstrated.

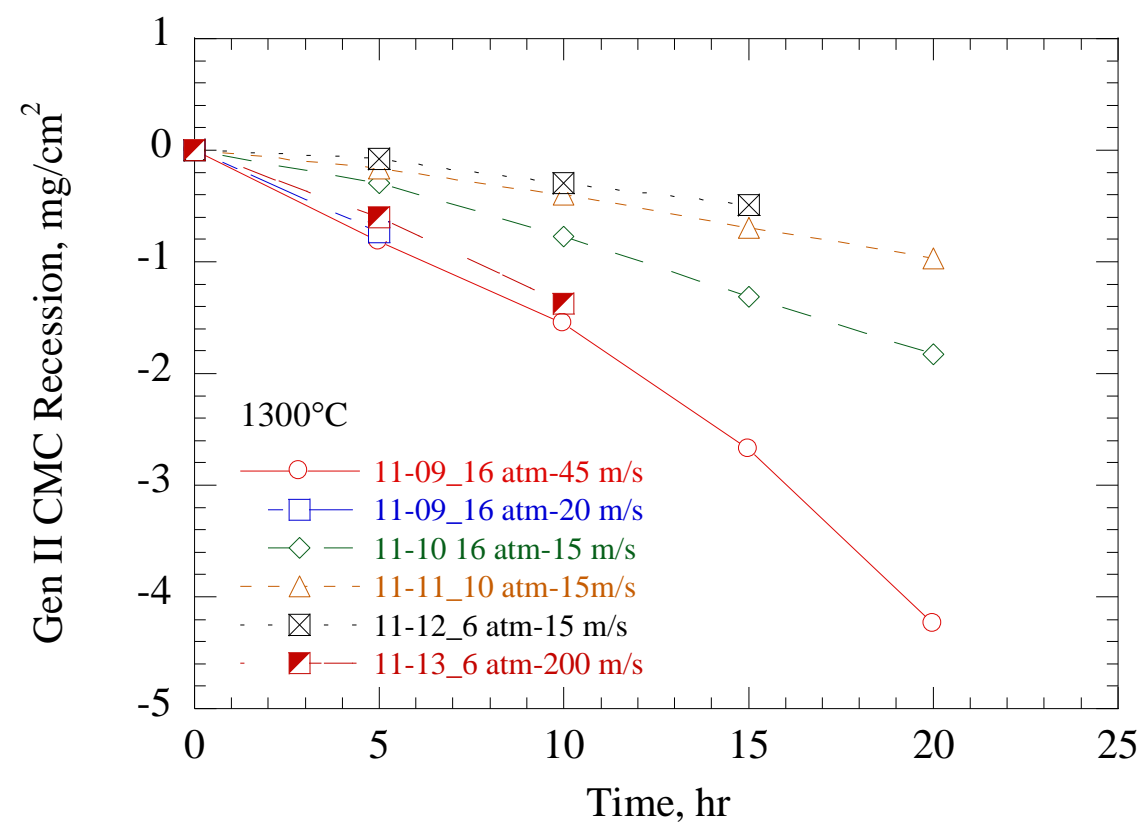

Figure 26: Recession data of the Gen II CMC under various pressures and impingement cooling velocities at 1300C.

\section{CMC Exhaust Nozzle}

CMC (ceramic matrix composite) exhaust mixer nozzle technology is being matured for use in subsonic jet engines. This technology can allow hotter operating temperatures, increased thermal margin, improved fuel efficiency, weight reduction, increased component durability, and engine noise reduction. The objective is to explore the potential benefits of utilizing an oxide/oxide CMC exhaust mixer and tail cone, and advance the technology to TRL 6. It is necessary to verify the ability to maintain lobe shape at high temperature in order to achieve improved mixing effectiveness and performance.

NASA's approach is to partner with industry and other government agencies and to collectively mature the CMC nozzle technology. NASA is collaborating with the FAA CLEEN program to develop advanced CMC nozzle components that utilize 3D CMC face sheet sandwich structures. A NASA-led ERA CMC nozzle effort is being conducted and coordinated with Boeing R\&T, where NASA is focused on demonstrating 3D CMC face sheet sandwich structures which offer improved durability, weight reduction, and manufacturability. NASA is also teaming with Rolls-Royce Liberty Works (RRLW) and ATK COI Ceramics, Inc. to fabricate and test a full-scale oxide-oxide mixer nozzle based on test results of a subscale nozzle designed for true flight environment. The subscale hardware will be designed and fabricated to assess manufacturability, aero-performance (mixing effectiveness, mixer pressure loss, and nozzle temperature and pressure profiles), and noise suppression. The Fullscale hardware will be designed for a relevant engine and will include: vibration testing at NASA GRC and potentially a ground-based engine test by RRLW (see Figure 27). 
The results to date are summarized below:

- Boeing has fabricated 3D CMC face sheet sandwich structure test articles, using 3D weaves (N610 fiber) selected and procured by NASA. Testing is expected to complete by December of 2012 .

- NASA has teamed and cost-shared with RRLW and ATK COIC, Inc. to design, fabricate, and conduct limited testing of a subscale CMC mixed flow nozzle for a next generation turbofan engine.

- Subscale CMC hardware was tested in two facilities: ASE FluiDyne Channel 11 Thrust Rig for aeroperformance and the NASA GRC Aero-Acoustic Propulsion Laboratory (AAPL) for acoustics results. These successful tests have led to the current effort to fabricate and test a full-scale mixer nozzle.

- A vibration/shaking test of a full scale CMC mixer nozzle will be performed at NASA GRC to 1) assess the durability of the hardware (at room temperature and $700^{\circ} \mathrm{F}$ ) and 2) tdemonstrate that such a component has the structural integrity required to survive ground-based engine testing.
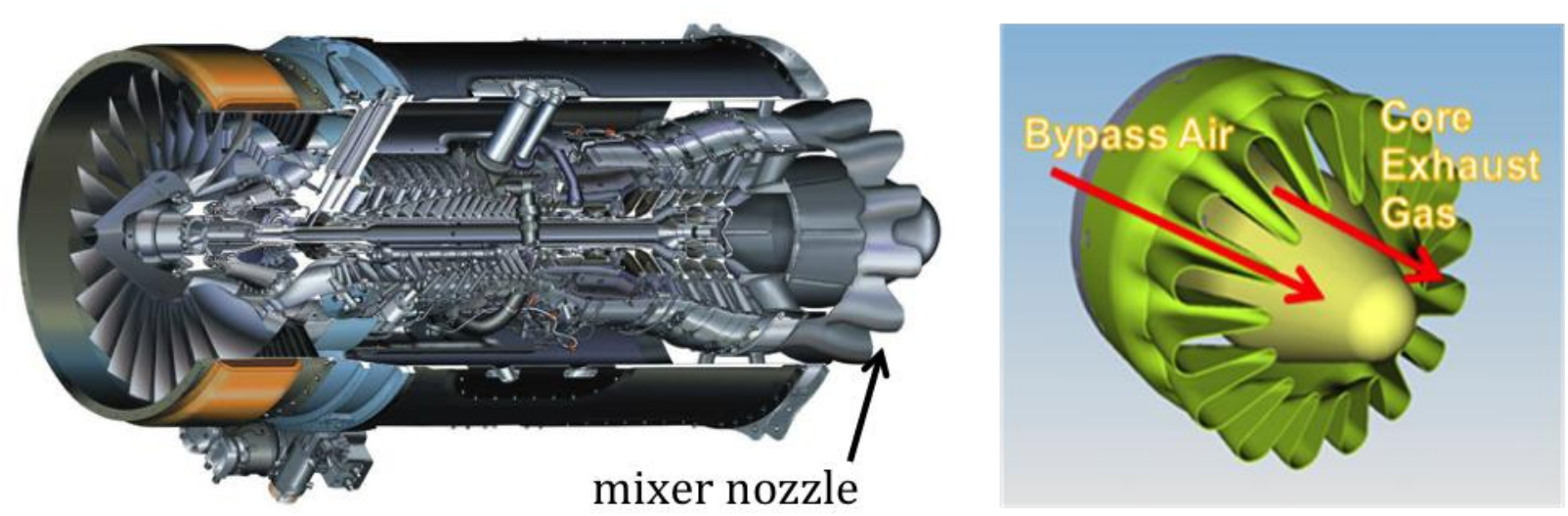

Figure 27: CMC oxide-oxide mixer nozzle being designed to replace metallic mixer nozzles such as the one shown on the AE2007 engine.

\section{Summary and Concluding Remarks}

Combustion, propulsor, and core technologies are being developed and demonstrated in the ERA project to enable an aircraft that reduces fuel burn by 50\%, reduces Landing and Take-off Oxides of Nitrogen emissions by $75 \%$ relative to the CAEP 6 guidelines, and reduces cumulative noise by 42 Decibels relative to the Stage 4 guidelines. The reductions in fuel burn, emissions, and noise are based on a reference mission of $3000 \mathrm{~nm}$ flight of a Boeing 777-200 with GE90 engines. The benefits of the technologies developed in the ERA project have been assessed and the results indicate the advanced engines ( i.e. open rotor) can reduce the fuel burn by $25 \%$ and the LTO NOx goal of 75\% reduction below CAEP 6 is feasible. Noise assessments are still underway but are very dependent on aircraft configuration. System studies indicate a conventional tube and wing design with advanced technologies cannot meet the ERA noise goal of $42 \mathrm{~dB}$ below stage 4 . However, advanced aircraft configurations such as a blended wing body aircraft does provide the best opportunity to meet the noise goals due to the noise shielding provided by the aircraft. These technologies will continue to be developed and demonstrated as an integrated system to update the collective benefits of the technologies on aircraft systems.

\section{Acknowledgments}

The NASA Environmentally Responsible Aviation Project of the Integrated Systems Research Program sponsored this work. The technologies developed and described herein are attributed to the efforts of the following task leads for the ERA propulsion Technology portfolio: Chi Ming Lee, Clarence Chang, John Delaat, Mike Halbig, Dale Van 
Zante, Chris Hughes, Dave Arend, Mark Celestina, Doug Kiser and Martha Jaskowiak. Furthermore, the author is appreciative to Jim Heidmann for his thorough review and helpful discussions in the writing of this document. Additionally, the author wishes to extend his sincerest thanks to Dr. Fay Collier and the ERA Leadership team for their ERA project support and encouragement to promote this research to significantly reduce the impact of aviation on the environment by reducing the fuel burn, noise, and NOx emissions of future aircraft systems.

\section{References}

${ }^{1}$ Collier, Fayette, "Environmentally Responsible Aviation for Environmental Challenges Facing Aviation," Report NF1676L-1123 (URL:http://ntrs.nasa.gov), GARDN, First Green Aviation Conference, Feb 2011.

2Jimenez, Hernando, Pfaender, Holger, and Mavris, Dimitri, "System-wide Fleet Assessment of NASA Environmentally Responsible Aviation (ERA) Technologies and Concepts for Fuel Burn and CO” AIAA-20116882, $11^{\text {th }}$ AIAA Aviation Technology Integration, and Operations (ATIO) Conference, Virginia Beach, VA, Sep 20-22, 2011.

${ }^{3}$ Berton, J. and Guynn, M., "Multi-Objective Optimization of Turbofan Design Parameters for an Advanced SingleAisle Transport, “AIAA paper 2010-9168, AIAA 10 ${ }^{\text {th }}$ Aviation Technology, Integration, and Operations (ATIO) Conference, Sept 2010.

${ }^{4}$ Guynn, M., Berton, Fisher, K., Haller, W., Tong, M., and Thurman, D., "Refined Exploration of Turbofan Design Options for an Advanced Single-Aisle Transport Aircraft,” NASA TM-2011-216883, Jan 2011.

${ }^{5}$ Tong, Michael T., Jones, Scott M., Haller, William J., Handschuh, Robert F., "Engine Conceptual Design Studies for a Hybrid Wing Body Aircraft," NASA/ TM2009-215680, Nov 2009.

${ }^{6}$ Committee on Aviation Environmental Protection, Sixth Meeting, "Economic Analysis of NOx Emissions Stringency Options," Technical Report CAEP/6-IP/13, International Civil Aviation Organization, Montreal, Canada, 2004.

${ }^{7}$ Lee, Chi-Ming, Chang, Clarence, Herbon, John and Kramer, Stephen, "NASA Project Develops Next-Generation Low-Emissions Combustor Technologies" to be published in the proceedings of 51st AIAA Aerospace Sciences Meeting, Grapevine, Texas, January 7-10, 2013.

${ }^{8}$ DeLaat, J.C.; Kopasakis, G.; Saus, J.R.; Chang, C.T.; Wey, C.: “Active Combustion Control for Aircraft GasTurbine Engines - Experimental Results for an Advanced, Low-Emissions Combustor Prototype" 50th AIAA Aerospace Sciences Meeting, Nashville, TN, January 2012. AIAA-2012-0783.

${ }^{9}$ Garnier, V., “Aero Engines of the $21^{\text {st }}$ Century: Evolution or Revolution?" Presented at the $20^{\text {th }}$ ISABE Conference, Goteborg, Sep 15, 2011

${ }^{10}$ Van Zante, Dale, and Wojno, John, "The NASA/GE Open Rotor Research Campaign: ERA Diagnostics Test," Ultra-High Bypass Propulsion Technology Panel, ASME Turbo Expo 2011, Vancouver, Canada, June 2011.

${ }^{11}$ Van Zante, Dale E., “ NASA/GE Collaboration on Open Rotors - High Speed Testing,” Report E -17798 (URL: http://ntrs.nasa.gov), Acoustics Technical Working Group, NASA Glenn Research Center, May 2011.

${ }^{12}$ Van Zante, Dale, "Reestablishing Open Rotor as an Option for Significant Fuel Burn Improvements," Report HQSTI-11-013 (URL: http://ntrs.nasa.gov), AIAA 48th Joint Propulsion Conference, Jul 2012

${ }^{13}$ Van Zante, Dale; Wojno, John; "The NASA/GE Open Rotor Research Campaign: ERA Diagnostics Test," presentation at the ASME Turbo Expo 2011, Jun 2011.

${ }^{14}$ Van Zante, Dale; Gazzaniga, John; Elliott, David; and Woodward, Richard; “An Open Rotor Test Case: F31/A31 
Historical Baseline Blade Set,” ISABE -2011-1310, Sep 2011.

${ }^{15}$ Van Zante, Dale, Wernet, Mark, "Tip Vortex and Wake Characteristics of a Counterrotating Open Rotor, AIAA 48th Joint Propulsion Conference, Jul 2012.

${ }^{16}$ Van Zante, Dale, "The NASA Environmentally Responsible Aviation Project/General Electric Open Rotor Test Campaign" to be published in the proceedings of 51st AIAA Aerospace Sciences Meeting, Grapevine, Texas, January 7-10, 2013.

${ }^{17}$ Hughes, Christopher E., "Aircraft Engine Technology for Green Aviation to Reduce Fuel Burn," paper AIAA2011-3531-852, AIAA Atmospheric Space Environments Conference, Honolulu, HI, June 2011.

${ }^{18}$ Hughes, Christopher E., "NASA Collaborative Research on the Ultra High Bypass Engine Cycle and Potential Benefits for Noise, Performance and Emissions," ISABE -2009-1274, 2009.

${ }^{19}$ Hughes, Christopher E., NASA Glenn Research Center; Lord, Wesley, Pratt \& Whitney; "NASA/Pratt \& Whitney Collaborative Partnership Research in Ultra High Bypass Cycle Propulsion Concepts," Report E-16905 (URL: http://ntrs.nasa.gov), Fundamental Aeronautics Program 2nd Annual Review, Oct 2008

${ }^{20}$ Hughes, Christopher, "Geared Turbofan Technology," presentation at the NASA Green Aviation Summit, September 2010, URL: www.aeronautics.nasa.gov/pdf/hughes_green_aviation_summit.pdf.

${ }^{21}$ Hughes, Christopher, and Smith, Steven; "The Promise and Challenges of Ultra High Bypass Ratio Engine Technology and Integration,” Report HQ-STI-11-012 (URL: http://ntrs.nasa.gov), AIAA 49th Aerospace Sciences Meeting, Jan 2011.

${ }^{22}$ Hughes, C., and Edmane, E., "Overview of Recent Ultra High Bypass Engine Cycle -Based Scale Model Test Results," presentation at the Fundamental Aeronautics Program 3rd Annual Review, Sep 2009.

${ }^{23}$ Arend, D. J., Tillman, T. G., and O’Brien, W. F., “Generation After Next Propulsor Research: Robust Design for Embedded Engine Systems," AIAA Paper 2012-4041, $48^{\text {th }}$ AIAA/ASME/ SAE/ASEE Joint Propulsion Conference and Exhibit, July 30 - August 1, 2012.

${ }^{24}$ Hardin, L. W., Tillman, G., Sharma, O. P., Berton, J., and Arend, D. J., "Aircraft System Study of Boundary Layer Ingesting Propulsion," AIAA Paper 2012-3993, 48 ${ }^{\text {th }}$ AIAA/ASME/SAE/ ASEE Joint Propulsion Conference and Exhibit, July 30 - August 1, 2012.

${ }^{25}$ Florea, R. V., Matalanis, C., Hardin, L. W., Stucky, M., and Shabbir, A., "Parametric Analysis and Design for Embedded Engine Inlets," AIAA Paper 2012-3994, $48^{\text {th }}$ AIAA/ASME/SAE/ ASEE Joint Propulsion Conference and Exhibit, July 30 - August 1, 2012.

${ }^{26}$ Bakhle, M. A., Reddy, T. S. R., Herrick, G. P., Shabbir, A. and Florea, R. V., "Aeromechanics Analysis of a Boundary Layer Ingesting Fan," AIAA Paper 2012-3995, AIAA 48th AIAA/ASME/SAE/ASEE Joint Propulsion Conference \& Exhibit, July 29 - August 1, 2012.

${ }^{26}$ Ferrar, A. M., and O'Brien, W. F., "Fan Response to Total Pressure Distortions Produced by Boundary Layer Ingesting Serpentine Inlets," AIAA Paper 2012-3996, 48th AIAA/ASME/SAE/ASEE Joint Propulsion Conference and Exhibit, Atlanta, GA, July 29 - August 1, 2012.

${ }^{27}$ Bakhle, M. A., Reddy, T. S., Herrick, G. H., Florea, R. V., Voytovych, D., "High-Fidelity Analysis of a Boundary Layer Ingesting Fan," NASA Fundamental Aeronautics Program Technical Conference Presentation, Cleveland, $\mathrm{OH}$, March 13-15, 2012.

${ }^{28}$ Ferrar, A. M., and O’Brien, W. F., "Measurements of Fan Response to Boundary Layer Ingesting Inlet Distortion," NASA Fundamental Aeronautics Program Technical Conference Presentation, Cleveland, OH, March 13-15, 2012. 
${ }^{29}$ Ferrar, A. M., Schneck, W. C., and O’Brien, W. F., "Flow in a Boundary Layer Ingesting Serpentine Inlets," AIAA Paper 2011-5568, $47^{\text {th }}$ AIAA/ASME/SAE/ASEE Joint Propulsion Conference and Exhibit, San Diego, CA, July 31-August 3, 2011.

${ }^{30}$ Sharma, O. P., “Design of High-Performance Boundary Layer Ingesting Propulsion Systems,” IGTI Panel Lecture, June 2011.

${ }^{31}$ Florea, R. V., Hardin, L. W., Tillman, G., Shabbir, A., and Sharma, O. P., "Design of Airframe-Integrated, Distortion-Tolerant Propulsion Systems," NASA Fundamental Aeronautics Program Technical Conference Presentation, Cleveland, OH, March 15-17, 2011.

${ }^{32}$ O’Brien, W. F., Ferrar, A. M., and Arend, D. J., "Experimental Measurement of Transonic Fan Wake Response to Uniform and Simulated Boundary Layer Ingesting Inlet Flows," NASA Fundamental Aeronautics Program Technical Conference Presentation, Cleveland, OH, March 15-17, 2011.

${ }^{33}$ Tillman, G., Hardin, L. W., Moffitt, B. A., Sharma, O. P., Lord, W. K. Berton, J., and Arend, D. J., "System-Level Benefits of Boundary Layer Ingesting Propulsion. Invited Paper," $49^{\text {th }}$ AIAA Aerospace Sciences Meeting, Orlando, FL, January 4-7, 2011.

${ }^{34}$ Ferrar, A. M., O'Brien, W. F., Ng, W. F., Florea, R. V., and Arend, D.J., "Active Control of Flow in Serpentine Inlets for Blended Wing-Body Aircraft," AIAA Paper 2009-4901, $45^{\text {th }}$ AIAA/ASME/SAE/ASEE Joint Propulsion Conference and Exhibit, Denver, CO, August 2-5, 2009.

${ }^{35}$ Florea, R. V., Reba, R., VanSlooten, P. R., Sharma, O. P., Stucky, M., O’Brien, W. F., and Arend, D. J., "Preliminary Design for Embedded Engine Systems," AIAA Paper 2009-1131, 47 ${ }^{\text {th }}$ Aerospace Sciences Meeting and Exhibit, Atlanta, GA, January 5-8, 2009.

${ }^{36}$ Liou, Ming-Sing and Lee, Byung Joon, “ Minimizing Inlet Distortion for Hybrid Wing Body Aircraft,” Journal of Turbomachinery, Vol 134, May 2012

${ }^{37}$ Tong, M.T., “An Assessment of the impact of Emerging High-Temperature Materials on Engine Cycle Performance, GT2010-22361, ASME TURBO EXPO 2012, Jun 2010.

${ }^{38}$ Celestina, Mark L, Fabian, John C., and Kulkarni, Sameer, "NASA Environmentally responsible Aviation High Overall Pressure Ratio Compressor Research - Pre-Test CFD,’AIAA 48th Joint Propulsion Conference, Jul 2012.

${ }^{39}$ DiCarlo, J.A. et al, "High Performance SiC/SiC Ceramic Composite Systems Developed for 1315C (2400F) Engine Components, NASA TM-2004-212729, 2004. Pp12-13.

${ }^{40}$ Zhu, D, Miller, R.A., Fox, D.S., "Thermal and Environmental Barrier Coating Development for Advanced Propulsion Engine Systems,” NASA TM-2008-215040.

${ }^{41}$ Jaskowiak, Martha, DiCarlo, James, Bhatt, Ram, Zhu, Dongming, Phillips, Ronald, Rauser, Richard, and Gorican, Daniel. "SiC/SiC Composites Evaluated for Turbine Vane Applications Under NASA's ERA Program," Proceedings of the 36th Annual Conference on Composites, Materials, and Structures, January 23-26, 2012, in Cocoa Beach / Cape Canaveral, Florida.

${ }^{42}$ Halbig, Michael, Jaskowiak, Martha, Kiser, James, and Zhu, Dongming, "Development and Demonstration of Ceramic Matrix Composite Technology for Aircraft Turbine Engine Applications," to be published in the proceedings of 51st AIAA Aerospace Sciences Meeting, Grapevine, Texas, January 7-10, 2013. 